\title{
PhiC31/PiggyBac modified stromal stem cells: effect of interferon $\gamma$ and/or tumor necrosis factor (TNF)-related apoptosis-inducing ligand (TRAIL) on murine melanoma
}

Vahid Bahrambeigi ${ }^{1,2}$, Nafiseh Ahmadi ${ }^{1}$, Stefan Moisyadi ${ }^{3,4}$, Johann Urschitz ${ }^{3}$, Rasoul Salehi ${ }^{2}$ and Shaghayegh Haghjooy Javanmard ${ }^{1,5^{*}}$

\begin{abstract}
Background: TRAIL and IFNy are promising anti-cancer cytokines and it has been shown that IFNy may sensitize cancer cells to TRAIL. Adipose derived mesenchymal stem cells (ADSCS) are attractive vehicles for delivering anti-cancer agents. In this study, we evaluated the therapeutic potential of PhiC31 ( $\varphi$ C31) recombinase and/or piggyBac transposase (pBt) modified ADSCs expressing either TRAIL, IFNy, or co-expressing TRAIL/IFNy in mouse models of melanoma.

Methods: The expression and bioactivity of mouse IFNY and TRAIL in $\varphi C 31$ and pBt modified cells were confirmed. We examined the effects of modified ADSCs on signal intensity of red fluorescence protein expressed by melanoma cells in subcutaneous tumors or established lung metastases and on survival (6 mice per group). We also conducted a flow cytometric analysis of systemic $\mathrm{CD}^{+} \mathrm{CD}^{2} 5^{+} \mathrm{FOXP3}^{+} \mathrm{T}$ regulatory cells (Tregs) and histological analysis of melanoma tumors. Data were analyzed by Student t test, ANOVA, and log-rank tests. All statistical tests were two-sided.

Results: We demonstrated non-viral DNA-integrating vectors can be used for stable transgene expression. IFNy inhibited melanoma cell growth in vitro probably via IFNY-induced JAK/STAT1 signaling pathway activation. Murine TRAIL induced apoptosis in the human cell lines CAOV-4 and Ej-138, while MCF7 and B16F10 cells appeared to be insensitive to TRAlL. Treatment of melanoma cells with IFNy did not influence their response to TRAIL. In contrast, results from in vivo studies showed that IFNY-expressing ADSCs, engrafted into tumor stroma, inhibited tumor growth and angiogenesis, prevented systemic increase of Tregs, increased PD-L1 expression and CD8+ infiltration (but not interleukin-2+ cells), and prolonged the survival of mice ( 68 days, $95 \%$ confidence interval $[\mathrm{Cl}]=52$ to 86 days compared to 36 days, $95 \% \mathrm{Cl}=29$ to 39 days for control, $P<.001)$.
\end{abstract}

Conclusions: For the first time, we employed DNA integrating vectors for safe and stable modification of MSCs. Our data indicate potential of non-virally modified IFNY-expressing ADSCs for treatment of melanoma through direct effects of IFNY. This study may have a significant role in the management of cancer in the future.

Keywords: PhiC31 integrase, PiggyBac transposase, Adipose derived mesenchymal stem cell, Interferon Y, TRAlL, Murine melanoma

\footnotetext{
*Correspondence: sh_haghjoo@med.mui.ac.ir

'Applied Physiology Research Center, Isfahan University of Medical Sciences, Isfahan, Iran

${ }^{5}$ Department of Physiology, Applied Physiology Research Center, School of Medicine, Isfahan University of Medical Sciences, Isfahan, Iran

Full list of author information is available at the end of the article
} 


\section{Background}

Mesenchymal stem cells (MSCs) are emerging as promising tools for combined cancer gene/cell therapies since they have the unique ability of targeting tumor cells [1]. Several recent studies have successfully used viral-based gene transfer approaches to modify MSCs. However, immunogenicity, risk of insertional mutagenesis, and accidental production of self-replicating viruses are of concern and remain a problem for viral systems [2]. Non-viral gene delivery methods represent a simpler and safer alternative, as long-term expression of the therapeutic genes can be achieved though their stable integration into the host genome using DNA-based gene transfer vectors. Commonly used non-viral integrating vectors permanently integrate DNA into the host genome via either a recombinase or transposase [3]. PhiC31 ( $\varphi \mathrm{C} 31)$ recombinase and piggyBac transposase $(\mathrm{pB} t)$ are two representatives of DNA-based gene transfer vectors that are under intensive development $[4,5]$. The site-specific recombinase of bacteriophage $\varphi \mathrm{C} 31$ integrates the complete plasmid construct carrying an $a t t B$ sequence into pseudo attP site in the mammalian genome [2]. Compared to $\varphi \mathrm{C} 31, \mathrm{pB} t$ insert only the transposon cassette including the transgenes situated inside of terminal repeat elements (TREs) [6]. We used the $\varphi \mathrm{C} 31$ and $\mathrm{pB} t$ systems to achieve long term gene expression of therapeutic agents in murine adipose derived MSCs (ADSCs).

The cytokine type II interferon (IFN $\gamma$ ) can be used as a therapeutic agent as it exerts a variety of different anti-tumor effects, including inhibition of cancer cell proliferation, repression of tumor angiogenesis, and the induction of tumor cell apoptosis $[7,8]$. IFN $\gamma$ also stimulates the host immune response and enhances tumor cell apoptosis via tumor necrosis factor (TNF)-related apoptosis-inducing ligand (TRAIL) [9]. TRAIL in its role as a death ligand binds to the surface death receptors (DR; DR1 and DR2) and induces apoptosis in a variety of neoplastic cells while sparing most normal cells. Cancer cells have variable levels of sensitivity to TRAILmediated apoptosis [10] and studies have shown that IFN $\gamma$ pre-treatment can sensitize some of the resistant cancer lines to TRAIL [11-15]. Besides, IFN $\gamma /$ TRAIL combination immunotherapy has been shown to synergistically induce tumor cell death [16]. However, to yield significant anti-tumor activity, multiple high-dose systemic administration of these cytokines is necessary which is associated with adverse side effects $[10,17]$. To overcome this limitation, several studies used cytokineexpressing MSCs to mitigate cancer progress in tumor models including melanoma [18-20]. Therefore, in this study we aimed to investigate antitumor activity of $\varphi \mathrm{C} 31 / \mathrm{pB} t$ modified murine ADSCs expressing IFN $\gamma$ and TRAIL individually, or co-expressing Trail/IFN $\gamma$ in vitro and in mouse subcutaneous or lung metastasis models of melanoma.

\section{Results}

\section{Characterization of murine ADSCs}

The authenticity of ADSCs was verified by differentiation experiments (Figure 1) along with immunophenotypic analysis of surface antigenes (Figure 2). ADSCs were isolated based on their adherence to the surface of culture dishes. Isolated cells expanded rapidly and in the third passage uniformed cells were obtained. Cells from passage 6 were used for characterization experiments. Plasticity of ADSCs was confirmed by differentiation of isolated ADSCs (Figure 1A) to adipocytes (Figure 1B), chondrocytes (Figure 1, C and D) and osteoblasts (Figure 1, E and F). Appearance of red colored lipid vacuoles in Oil red $\mathrm{O}$ staining, green colored mucopolisaccarides in Alcian blue staining, purple colored proteoglycans in Toluidin blue staining, red colored calcium deposits in Alizarin red staining and black colored mineralized deposits in Von Kossa staining demonstrated successful differentiation of ADSCs into three different cell lineages. Immunotyping of ADSCs revealed expression of stem cell markers CD73, CD90.1, CD105, CD146 and MSC-homing marker CXCR4. Moreover, a small sub-population of ADSCs showed a weak expression of stem cell markers CD24 and CD133. We did not detect any expression of surface markers CD11b, CD25, CD34, CD45 and CD309, confirming that our ADSC preparations did not contain any hematopoietic or endothelial cells (Figure 2).

\section{Stable modification of ADSCs and melanoma B16f10 Cells by DNA integrating vectors}

There is little information available regarding nucleofection of murine ADSCs. In this study, we achieved a transfection efficiency of $\sim 71 \%$ using the Human MSC Nucleofector kit with program X-001 and plasmid pMax (a vector expressing EGFP) (Figure 3, A, Left). ADSCs expressing enhanced green fluorescent protein (EGFP), IFN $\gamma$, TRAIL and co-expressing IFN $\gamma /$ TRAIL are respectively referred to EGFP-ADSC, IFN $\gamma$-ADSC, TRAIL-ADSC and IFN $\gamma$ /TRAIL-ADSC. FACS analysis of ADSCs nucleofected with pmhyGENIE-3-EGFP revealed that $\sim 75 \%$ of ADSCs were EGFP-positive after two weeks of culture under antibiotic selection (Figure 3, A, Right). Furthermore, a microscopic evaluation of these cells confirmed their efficient modification (Figure 3, B). Melanoma B16F10 cells, stably transformed and grown for 2 weeks under geneticin or zeocin selection, uniformly expressed Red fluorescent protein (RFP) (Figure 3, C) and EGFP (Figure 3, D) respectively (referred as RFP-melanoma and GFP-melanoma). High levels of IFNY expression were confirmed by Western blot analysis as indicated by a $19 \mathrm{kD}$ band in IFN $\gamma$-ADSCs (Figure 3, E). FACS analysis of cells stained with 


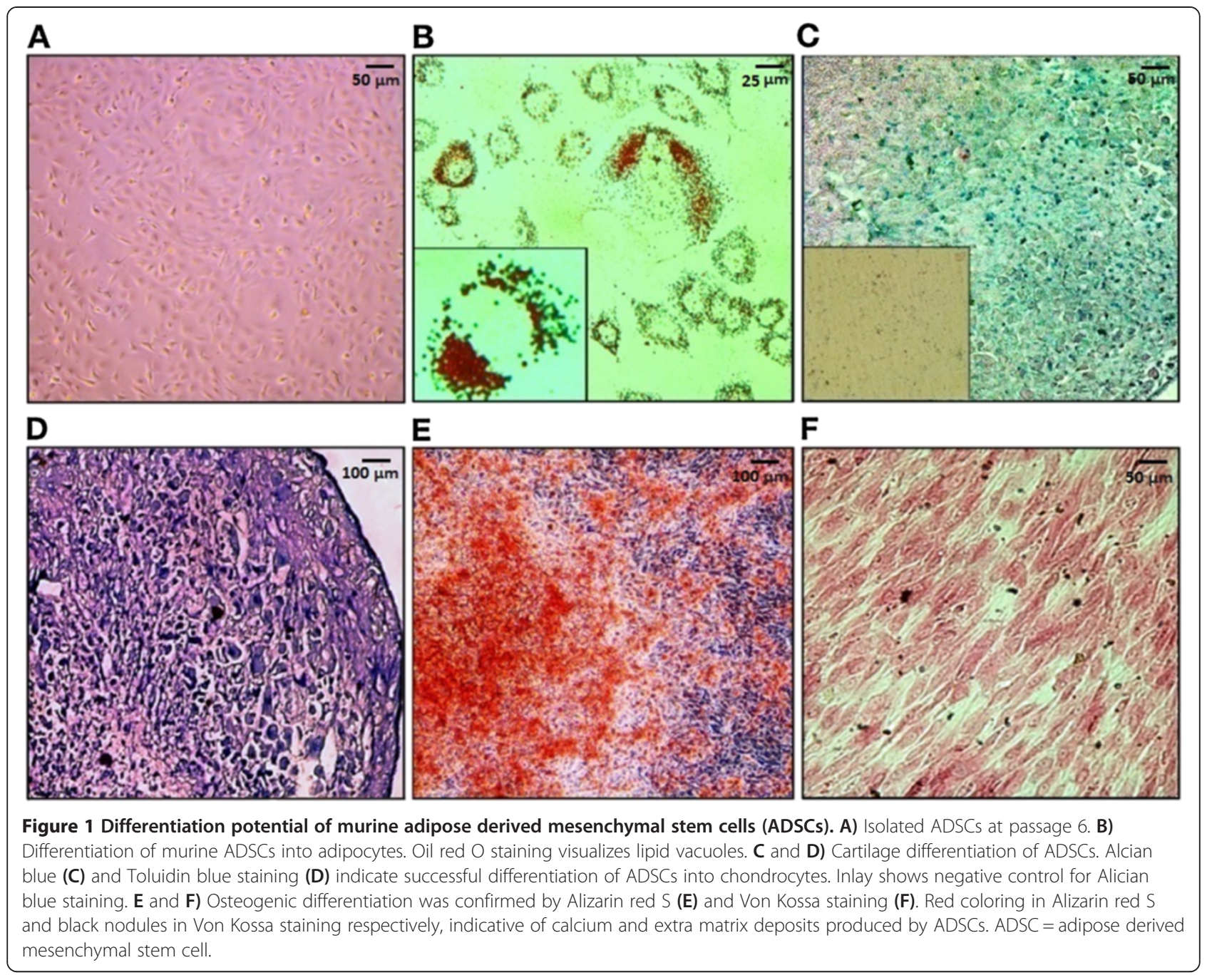

fluorescently-labeled anti-TRAIL antibody confirmed a relevant protein expression in TRAIL-ADSCs and the absence of TRAIL in EGFP-ADSCs (Figure 3, F).

\section{Effect of IFNY on viability and apoptosis of melanoma cells and the possible involvement of JAK/STAT1 dependent signaling pathway}

To evaluate the effect of IFN $\gamma$ on the proliferation of melanoma cells we incubated B16F10 cells with $100 \mu \mathrm{l}$ of culture medium (CM) supernatant from IFN $\gamma$ ADSCs. We determined the IFN $\gamma$ concentration by ELISA at about $1800 \mathrm{pg}$ per $\mathrm{mL}$ of CM. We evaluated the Melanoma cell proliferation and apoptosis by the 3(4,5-Dimethylthiazol-2-yl)-2,5-diphenyltetrazolium bromide (MTT) and Annexin V apoptosis assays. For MTT assay, melanoma cells were incubated in CM from either EGFP-ADSCs or IFN $\gamma$-ADSCs. Zeocin, a proliferation inhibitor, was used as a positive control $\left(10^{4} \mu \mathrm{g} / \mathrm{mL}\right)$ to monitor apoptosis. Recombinant mouse IFN $\gamma$ was used to evaluate the effect of purified IFNY on the proliferation of melanoma cells. All samples were compared to mock. The results from MTT assays, shown in Figure 4A demonstrated a statistically significant decrease in viability of these melanoma cells, similar to the bioactivity effect of purified mouse IFNY (ANOVA, $P<.001$; Mean percent are shown on Additional file 1: Table S1). As a subsequent step, we assessed the potential of IFNY on apoptosis of melanoma cells using Annexin V apoptosis assay. Results shown in Figure 4, B and C indicated that incubation of melanoma cells with IFNY-containing $\mathrm{CM}$ induces early apoptosis of melanoma cell over the incubation period in a statistically significant manner (ANOVA, $P<.001$ ). The mean percentage of early apoptosis in melanoma cells during the incubation period of 24 hours with supernatant from IFN $\gamma$-ADSC increased from $\sim 18$ to $\sim 43 \%$ while melanoma cells treated with mock supernatant showed only $\sim 11$ to $\sim 17 \%$ of early apoptosis (Additional file 1: Table S2). Additionally, we investigated whether IFN $\gamma$ produced by IFN $\gamma$-ADSCs can activate the JAK/STAT1 dependent signaling pathway in melanoma cells. For this purpose we prepared two types of 


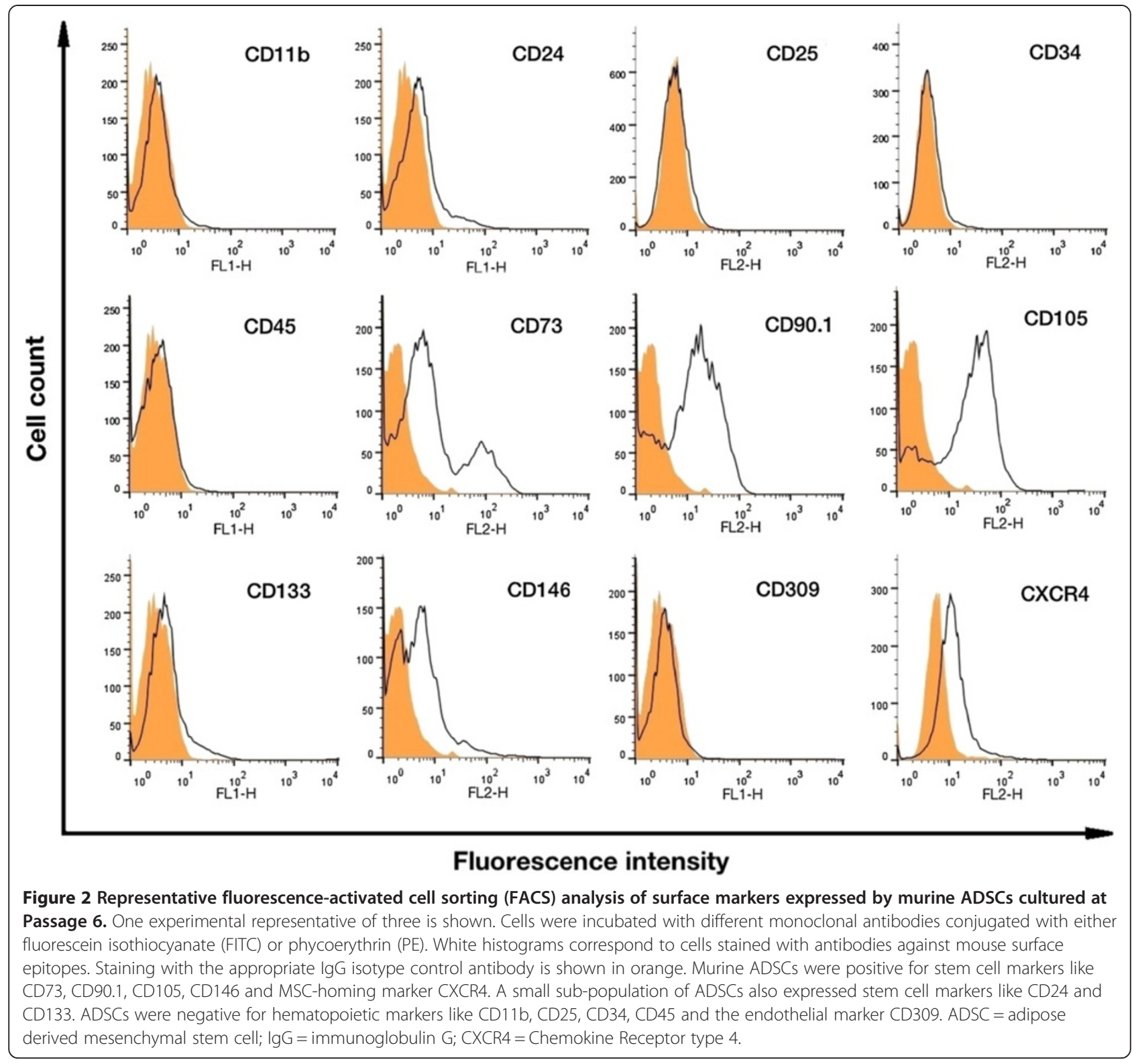

permanently modified melanoma B16F10 cells. The first set of cells contained the firefly luciferase gene under direct repeats of the interferon-stimulated response element (ISRE) and a minimal TA promoter (referred herein as ISRE/FL-melanoma cells). The second set of melanoma cells were modified to constitutively express firefly luciferase under the control of a cytomegalovirus (CMV) enhancer, a chicken beta actin and rabbit beta globin intron (CAG) promoter (referred to as FL-melanoma cells and used as positive control cells). FL-melanoma and ISRE/ FL-melanoma cells were incubated with supernatants from either EGFP-ADSCs or IFN $\gamma$-ADSCs for 48 hours. The analysis of the visible luminescence signal intensity clearly demonstrated IFN $\gamma$-induced Jak/STAT-mediated signal activation in ISRE/FL-melanoma cells (Figure 4D).

\section{Bioactivity of TRAIL and In Vitro effect of IFNy on} sensitization of melanoma cells

To explore the bioactivity of TRAIL, triplicate co-culture experiments were performed. Wild type ADSCs (WTADSCs) or TRAIL-ADSCs were co-cultured with CAOV-4, Ej-138, MCF-7, or B16F10 cells (Figure 5A). We observed an effect of murine TRAIL in CAOV-4 and Ej-138 lines. The mean mortality rate increased in a statistically significant manner from $13.41 \pm 1.2 \%$ to $33.72 \pm 5.1 \%$ and 6.36 $\pm 0.6 \%$ to $22.2 \pm 2.4 \%$ for CAOV- 4 and Ej-138 respectively (t-test, $P<.001)$. TRAIL-ADSCs had no effect on the other cell lines (t-test, $P=.545$ for MCF-7 and $P=.28$ for B16F10). For the next step, we co-cultured melanoma cells with either WT-ADSC or TRAIL-ADSC, in mock CM or IFNy-containing $\mathrm{CM}$, and for $12 \mathrm{~h}$ and $48 \mathrm{~h}$ (Figure 5B). 


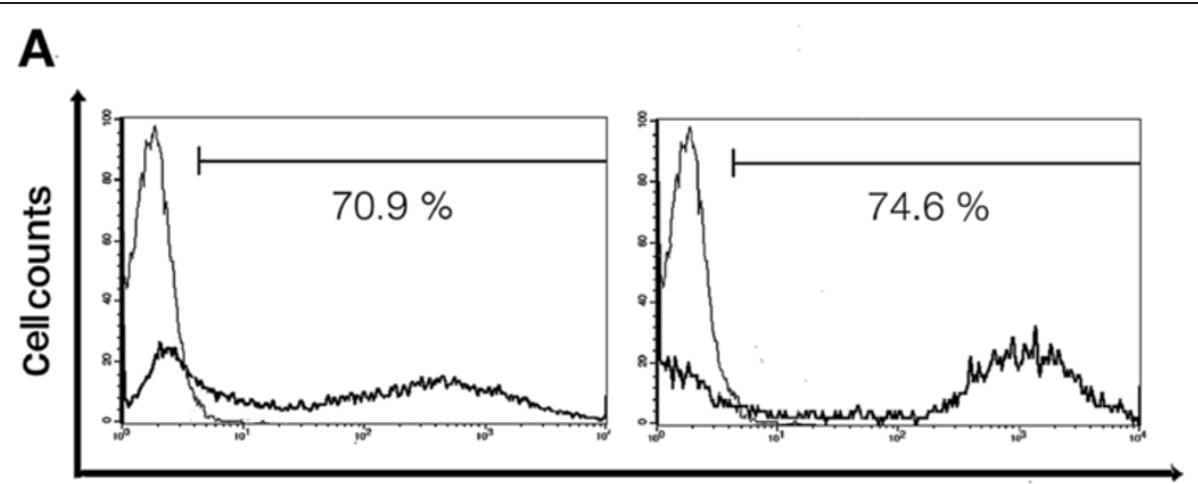

Fluorescence intensity

B

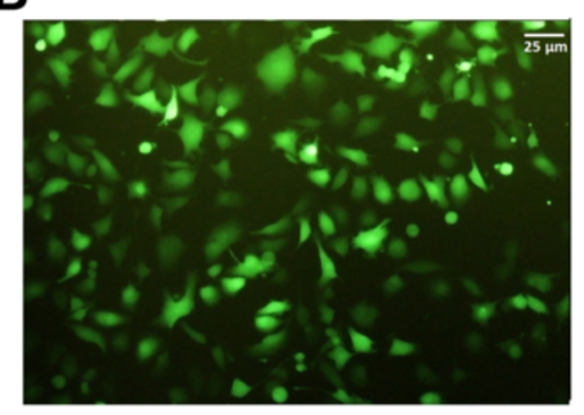

D

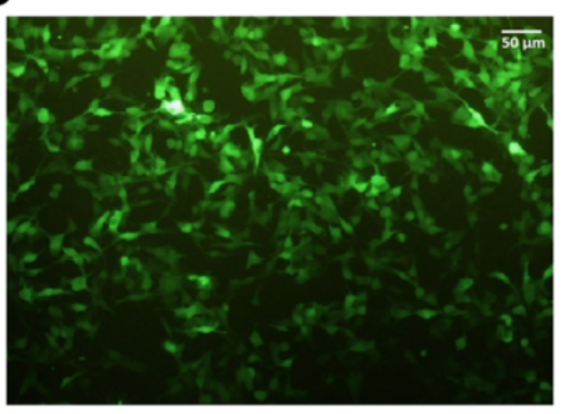

$\mathbf{F}$

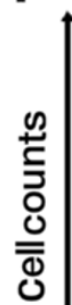

$F$
C

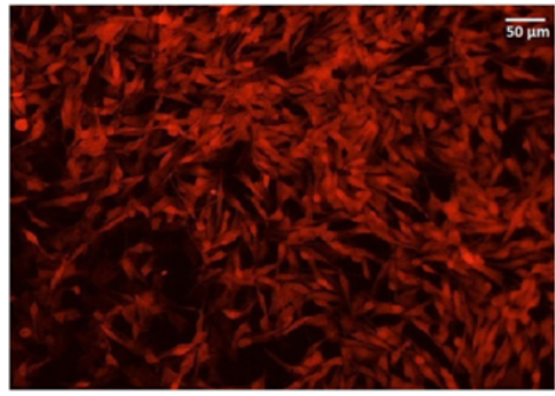

E

EGFP-ADSC IFN $\gamma$-ADSC
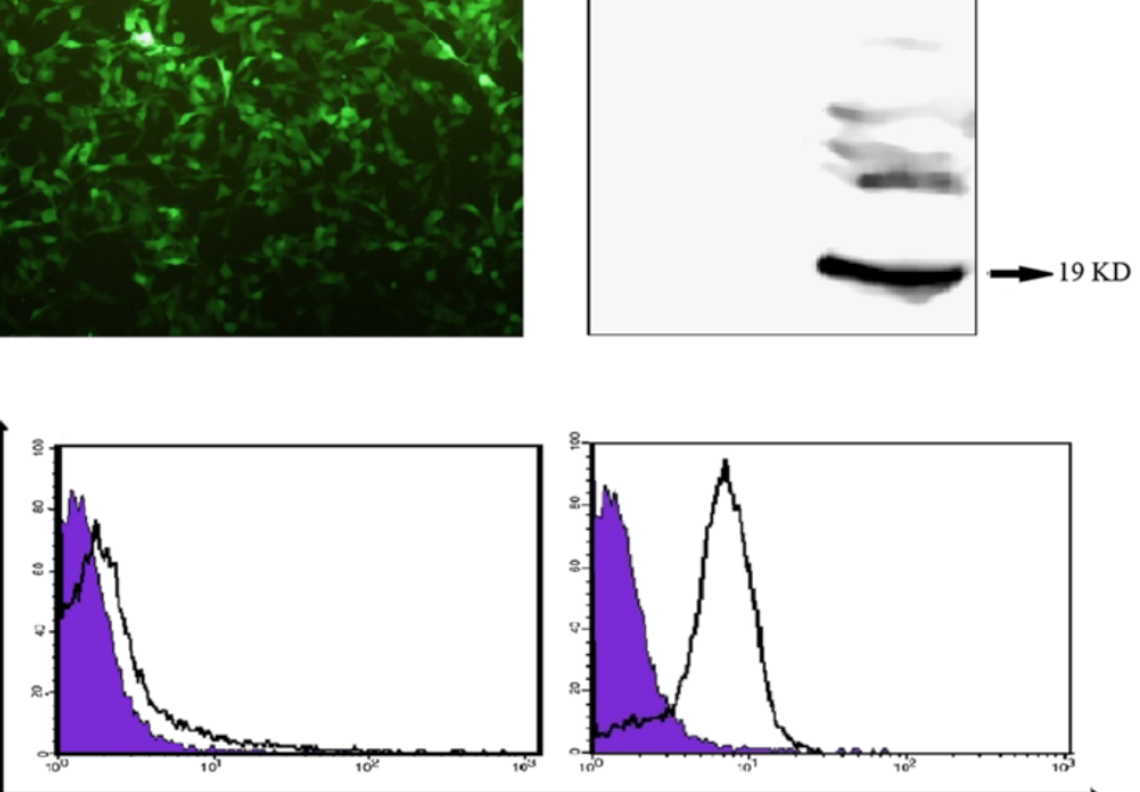

Fluorescence intensity 
(See figure on previous page.)

Figure 3 Stable modification of ADSCs and melanoma B16f10 cells with the use of DNA integrating vectors. A) Flow cytometric analysis of EGFP expression by ADSCS. (Left plot) Mean percentage of EGFP-expressing ADSCS post $48 \mathrm{~h}$ of nucleofection with pmaxGFP vector, indicating efficient transgene transfer into mouse ADSCs. (Right plot) Mean percentage of EGFP-positive ADSCs two weeks after nucleofection with pmhyGENIE-3 and hygromycin selection. Results are representatives of triplicate experiments. B) Fluorescence microscopy image of EGFP-expressing ADSCs after nucleofection with pmhyGENIE-3 and two weeks selection with hygromycin. C) Stable RFP-expressing melanoma cells after lipofection with pDsRed-attb-zeo/pCMVInt and three weeks of zeocin selection. D) EGFP-expressing melanoma cells after lipofection with pBEB/pCMVInt and three weeks of geneticin selection. E) Western blot analysis of IFNy from ADSC cell lysates. Modified ADSCS were selected with hygromycin following nucleofection with either pmhyGENIE-3 (Lane 1) or pmhyGENIE-3-IFNY (Lane 2). Blotting was performed using a monoclonal antibody against mouse IFNY. F) Cytofluorimetric evaluation of TRAIL expression in ADSCs selected with geneticin following co-nucleofection with pBEB/pCMVInt (Violet histograms) and pBTB/pCMVInt (white histograms). ADSCs were stained with a PE conjugated monoclonal antibody to mouse TRAlL. A single representative experiment of triplicates is shown. (Left plot) Surface staining of TRAll-ADSCs after $48 \mathrm{~h}$ of co-nucleofection. (Right plot) Surface staining of TRAll-ADSCs after co-nucleofection and three weeks of geneticin selection. $\mathrm{PE}=$ phycoerythrin.

The results demonstrated that a $48 \mathrm{~h}$ incubation of melanoma cells with either WT-ADSC or TRAIL-ADSC in the presence of IFNY reduced the melanoma cell numbers (ANOVA, $P<.001$ ). Shorter incubation periods with or without IFNy had no effect on melanoma cell numbers (Figure 5C).

\section{Plasma levels of IFN $\gamma$ after injection of IFNY-producing ADSCs to mice}

ELISA was performed to evaluate the effect of stem cell therapy on systemic levels of IFNY at three time points (days 10, 16, and 21). The systemic levels of IFNY in all of the experimental groups were below the detection level of our ELISA assay, indicating very low plasma levels.

\section{In Vivo effect of modified ADSCs on growth of subcutaneous melanoma and melanoma pulmonary tumors, and survival analysis of mice with melanoma metastases}

We examined the effects of modified ADSCs on signal intensity of red fluorescence protein expressed by melanoma cells in subcutaneous tumors or established lung metastases and on survival. For each model, mice were randomly divided into the following five experimental groups: injected with (a) PBS (control group), (b) EGFPADSCs, (c) TRAIL-ADSCs, (d) IFN $\gamma$-ADSCs and (e) IFN $\gamma /$ TRAIL-ADSCs. Each group consisted of 6 mice and the experiment for metastasis models was performed in duplicate. There was no observed adverse health effect related to the injection of ADSCs. In vivo optical imaging of mice with subcutaneous melanoma revealed a statistically significant reduction of melanoma tumor growth detected by red fluorescent signal in groups co-injected with IFN $\gamma$-expressing ADSCs (ANOVA, $P<.001$, Figure 6A). There was no additive effect on tumor ablation when IFN $\gamma /$ TRAIL-ADSCs were coinjected with the melanoma cells, indicating that presence of IFN $\gamma$ is solely responsible for tumor reduction (Figure 6, A and D, left panel). Co-inoculation of melanoma cells with EGFP-ADSC (ANOVA, $P=.592$ ) or TRAIL-ADSC $(P=.798)$ did not alter tumor growth. In lung metastatic models, metastatic colonies were observed in all treatment groups. Using ex vivo imaging we noticed the presence of several internal colonies that were not visible on the surface of the lungs (Figure 6B). However, the colony size and number was reduced in mice treated with IFN $\gamma$-ADSCs and IFN $\gamma /$ TRAIL-ADSCs in a statistically significant manner (ANOVA, $P<.001$, Figure $6, \mathrm{C}$ and $\mathrm{D}$, right panel). There was no change in tumor size of mice treated with EGFP-ADSCs $(P=.216)$ or TRAIL-ADSCs $(P=.907$, Figure 6, C and D, right panel). We examined whether genetically modified ADSC (GM-ADSC) treatments improved the overall survival of mice with melanoma lung metastases. Treatment of mice with IFN $\gamma$-ADSCs or IFN $\gamma / T R A I L-$ ADSCs demonstrated a statistically significant increase in the median survival of melanoma bearing mice, while most of the animals in other groups died by day 40 (Figure 7A). Results from the Pairwise log-rank test indicated there was no difference between survival of mice treated with IFN $\gamma$-ADSCs or IFN $\gamma /$ TRAIL-ADSCs (Additional file 1: Table S3). Results from immunohistochemistry (IHC) and TUNEL staining shown in Figure 7, B and C indicated a statistically significant decrease in melanoma cell proliferation (Ki67; $P<.001)$, tumor vasculature $(\mathrm{CD} 31 ; P<.001)$ and a statistically significant increase in melanoma cell apoptosis (TUNEL; $P<.001$ ). Immunostaining of pulmonary tumor sections revealed that injected IFN $\gamma$-producing ADSCs upregulate PD-L1 expression in melanoma lung tumor cells (compared to metastatic tumor samples from mice that received EGFP-ADSCs or remained untreated) (Figure 7B). Differentiation staining indicated there was no in vivo differentiation of ADSCs from different groups into three mesodermal lineages in tumor samples (Additional file 2: Figure S1, available online). However, some capillary-like structures of ADSCs were observed after IHC for EGFP and PD-L1 (Additional file 3: Figure S2, available online).

\section{Murine ADSC homing}

To evaluate the homing behavior of EGFP-ADSCs, which had been co-injected with RFP-melanoma cells, 


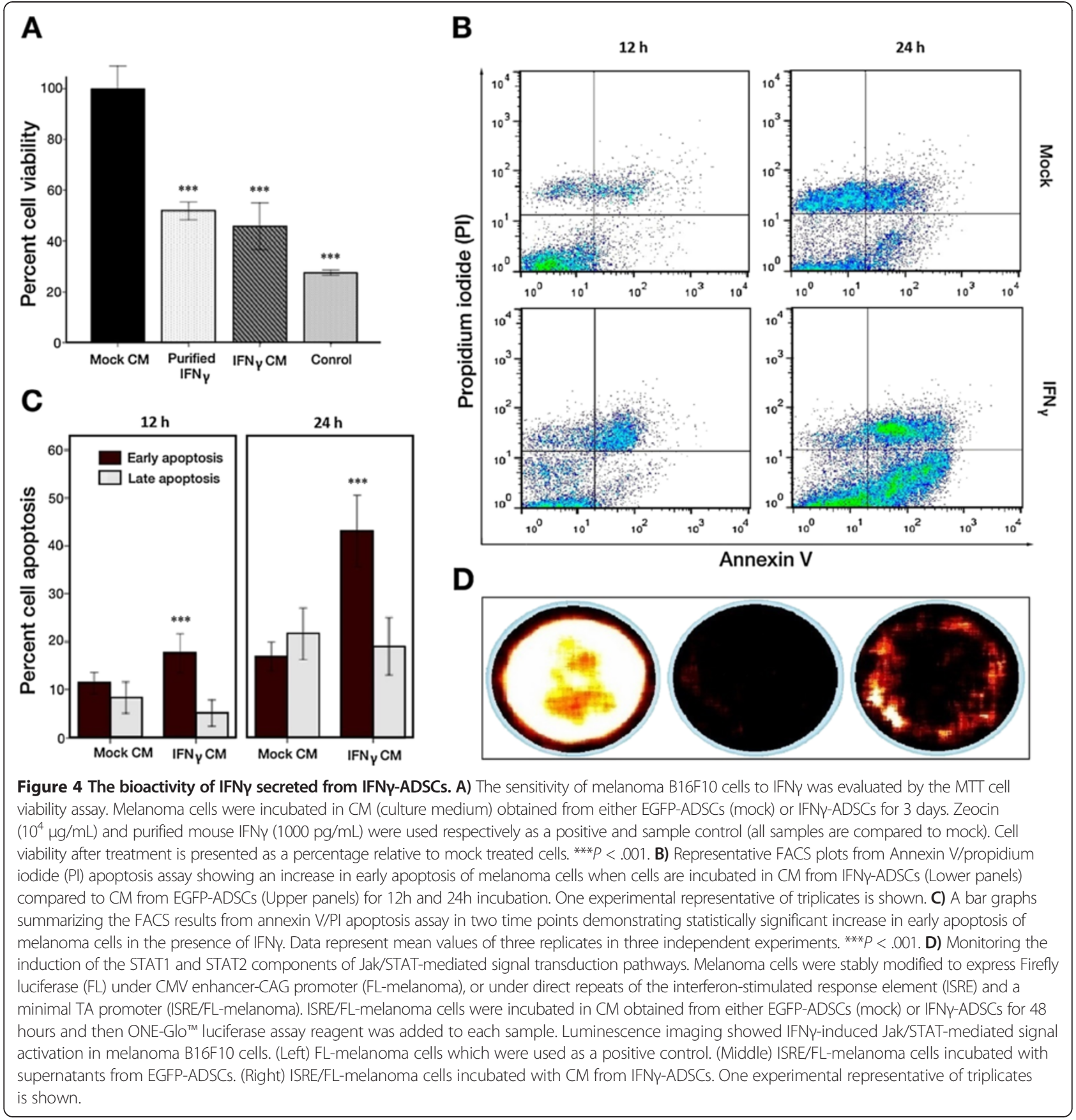

subcutaneous tumor bearing mice were analyzed 21 days post intravenous injection using a In-Vivo imaging system. We detected EGFP-ADSCs accumulating around the tumors (Figure $8 \mathrm{~A}$ ), a finding confirmed by IHC analysis of subcutaneous tumor sections (Figure 8A). Likewise, the IHC analysis for IFNY and TUNEL staining showed juxtaposition of IFN $\gamma$-ADSCs with melanoma cells (Figure 8E). We also tracked homing of EGFP-ADSCs and IFN $\gamma$ ADSCs to pulmonary B16F10 tumors. Melanoma nodules were harvested at day 28 post melanoma cell injection. The IHC analysis of melanoma lung tumor sections using a polyclonal anti-EGFP Ab indicated homing of $\sim 4.3$ of EGFP-positive cells to the melanoma metastases in the lung (Figure 8, B and C). IHC analysis of melanoma metastases using a monoclonal anti-mouse IFN $\gamma$ Ab showed $\sim 4.7$ of IFN $\gamma$-positive cells per 1000 melanoma tumor cells (Figure 8D). Detection of IFN $\gamma$ in the melanoma lung tumor samples confirmed prolonged expression of IFN $\gamma$ 


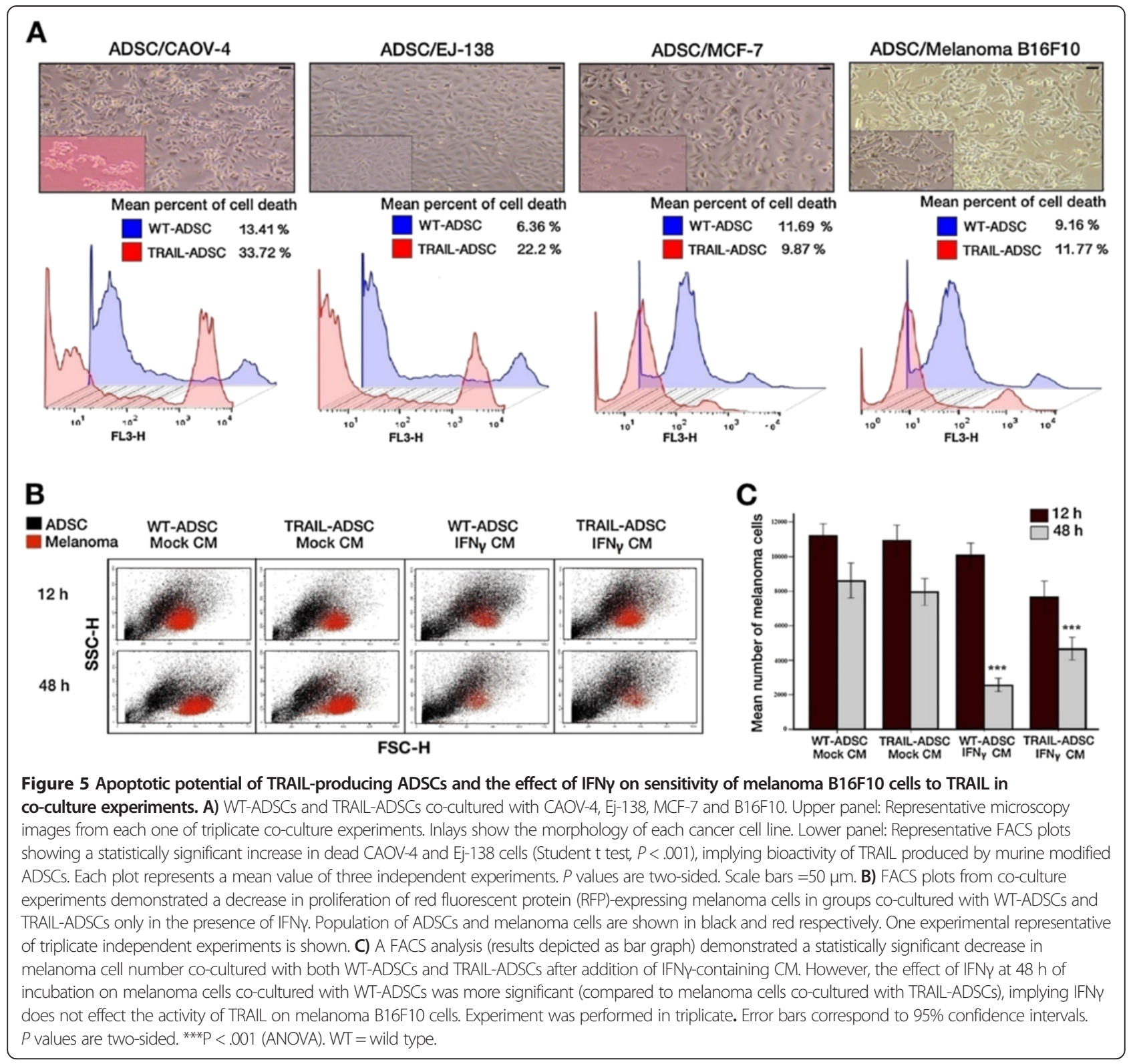

by IFN $\gamma$-ADSCs, most of which homed to the melanoma lung metastases and not to normal lung tissue (Figure 8F).

\section{The effect of cell therapy on infiltration of CD4+, CD8+ , FOXP3+ and IL2+ Cells}

We examined the infiltration of CD4+, CD8+, FOXP3+ and IL2+ cells to evaluate a potential participation of immune cells in GM-ADSC therapy experiments. An IHC analysis of metastatic lung tumors was performed at day 28 of the stem cell treatment. Metastatic lung tumors treated by IFN $\gamma$ revealed no statistically significant infiltration of $\mathrm{CD} 4+$, FOXP3+ and IL2+ cells compared to control group (Figure 9A, upper panel, respective microscopic images from control samples are shown), whereas there was a statistically significant increase in CD8+ cells
(ANOVA; $P<.001$, Figure 9B), indicating IFN $\gamma$-induced infiltration of CD8+ T cells (Figure 9A, lower panel).

\section{The effect of cell therapy on population of systemic CD4 ${ }^{+} \mathrm{CD}_{25}{ }^{+} \mathrm{FOXP}^{+} \mathrm{T}$ regulatory cells (Tregs)}

Population analysis of peripheral blood mononuclear cell (PBMC) isolated by Ficoll density gradient revealed two separate populations of PBMCs; lymphocytes and monocytes (Figure 9C, left panel). We initially analyzed PBMCs and lymphocytes for CD4 (Figure 9C, right panel) and subsequently CD4+ lymphocytes for $\mathrm{CD}_{2} 5^{+}$ $\mathrm{FOXP3}^{+}$by FACS analysis (Figure 9D). We noted that the mean percentage of $\mathrm{CD} 4+$ cells significantly decreased in ADSC-injected groups in a statistically meaningful manner (ANOVA, $P=.021$ for EGFP-ADSCs and 

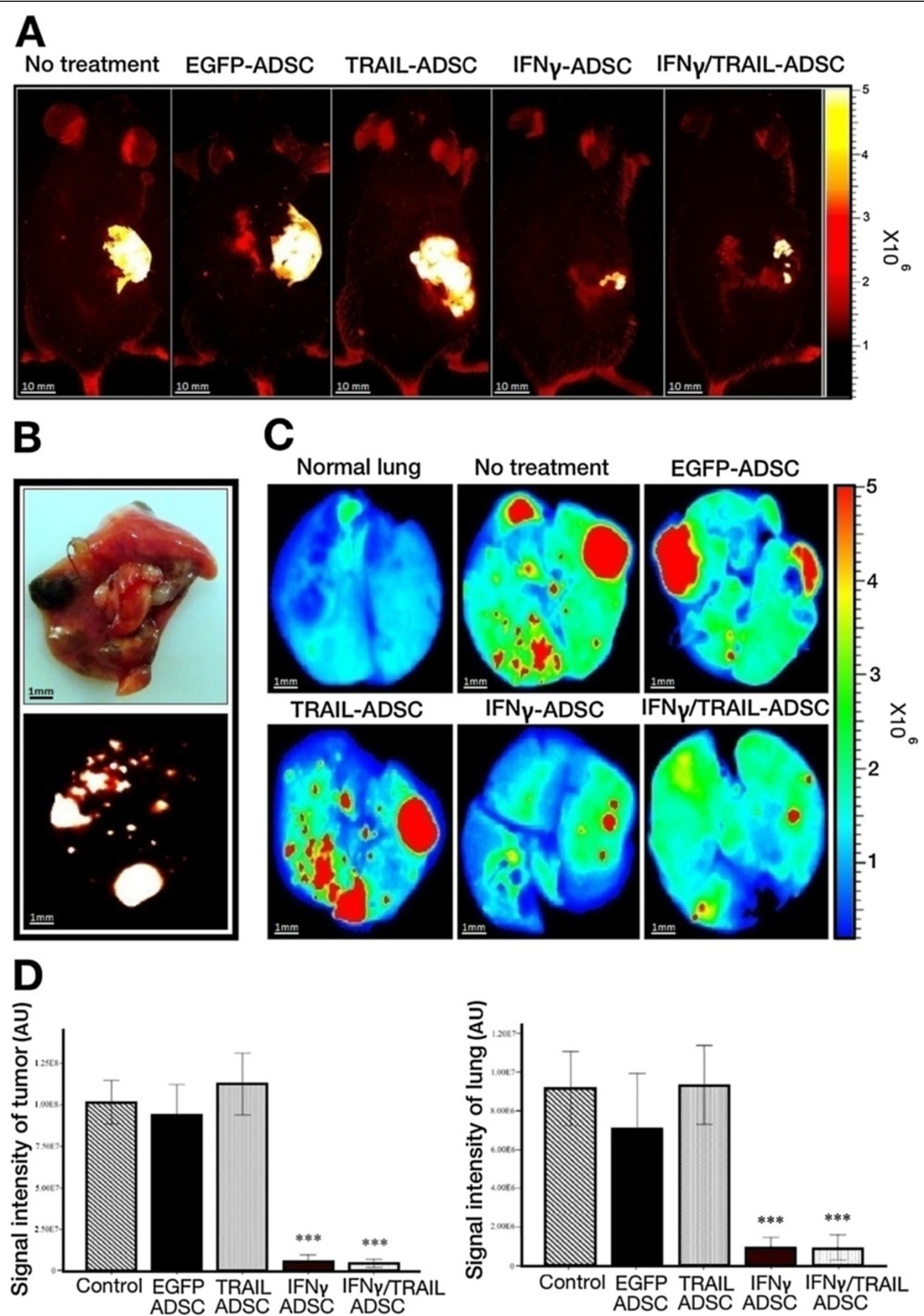

Figure 6 (See legend on next page.) 
(See figure on previous page.)

Figure 6 In vivo and ex vivo red fluorescence optical imaging obtained with the In-Vivo FX Pro small-animal imaging system.

A) Representative red fluorescence in vivo images of subcutaneous melanoma bearing mice in different treatment groups. Red fluorescence protein (RFP)-expressing melanoma cells in density of $2 \times 10^{6}$ were delivered either alone or concurrently with $7.5 \times 10^{5}$ of genetically modified ADSCS (GM-ADSCS). Mice were anesthetized with isoflurane and images were captured using a multi-wavelength source with a 2 min exposure time. B) Upper image showing a lung with RFP-melanoma lung metastases at day 28. Lower image, red fluorescence optical imaging of the same lung, indicating that some of RFP-melanoma metastases are not superficially visible. C) Representative red fluorescence ex vivo images of dissected lungs in different treatment groups. On day $0,7.5 \times 10^{5}$ of RFP-melanoma cells were injected into the lateral tail vein of mice. Ten days later, mice were given PBS or $7.5 \times 10^{5}$ of GM-ADSCs by tail vein injection. Mice were sacrified at day 28 for ex vivo optical imaging of lung samples, performed using a multi-wavelength source with a 2 min exposure time. D) Quantification of fluorescent signal intensities was performed using the Bruker Molecular Imaging Software. Fluorescence intensity was expressed as arbitrary units (AU) and was reported as a mean \pm SD in the bar graphs. (Left) Quantification of in vivo images (photons/s of subcutaneous tumor region). Bar graphs indicate significant subcutaneous tumor regression in mice that were treated with IFNy-expressing ADSCs, whereas tumors grew rapidly in the other groups. (Right) Quantification of ex vivo images (photons/s of lung region). Bar graphs demonstrating reduced red fluorescence intensity in lung samples from mice injected with IFNy-expressing ADSCs, while red fluorescence intensity significantly increased in other groups. Each group consisted of six mice. ***P $<.001$ (ANOVA).

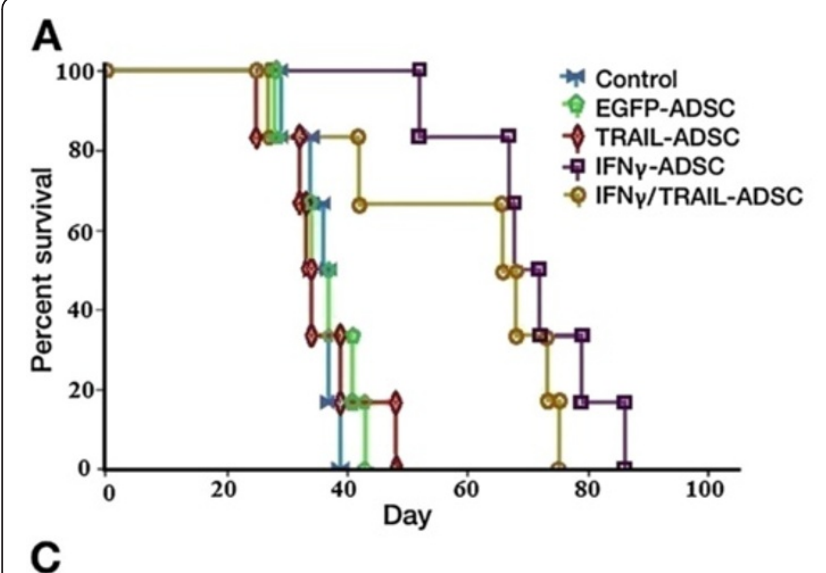

B
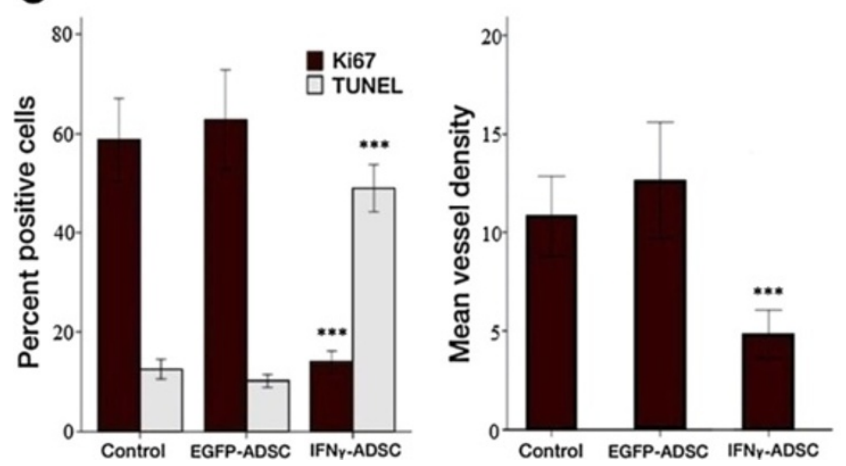
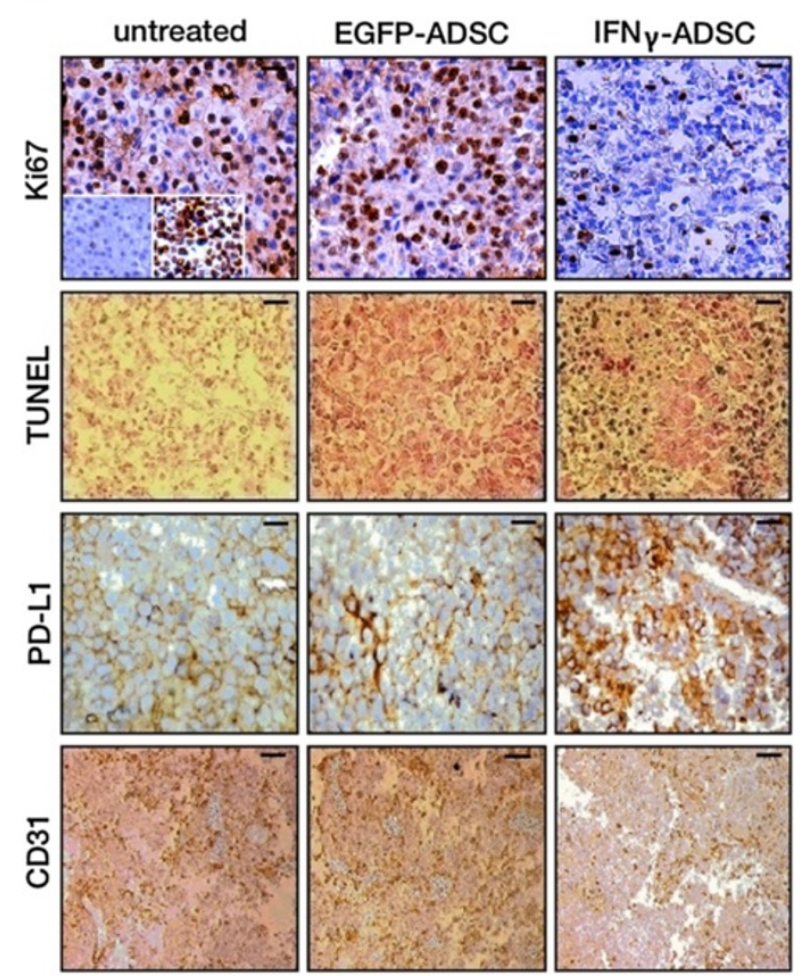

Figure 7 Long-term survival and melanoma lung tumor analysis. A) Survival of mice with established pulmonary metastases of B16F10 melanoma cells, intravenously injected with genetically modified ADSCs. An additional group of mice with established lung metastases derived from melanoma cells received only PBS (control group). Survival was measured from the day of melanoma cell injection until the day of death. Survival curves were drawn by the Kaplan-Meier method ( $n=6$ in each treatment group). B) Representative microscopic images of immunohistochemistry (IHC) staining for cell proliferation marker Ki67 (Inlays show negative control and positive controls), TUNEL staining for analysis of tumor cell apoptosis, IHC staining for PD-L1 (Scale bars $=50 \mu \mathrm{m}$ ), and IHC satining for neovasculature marker CD31 (Scale bar =100 $\mu \mathrm{m}$ ). Microscopic images clearly shows injected IFNY-expressing ADSCs significantly upregulate PD-L1 expression in melanoma lung tumor cells (compared to untreated control and EGFP-ADSC injected groups). C) Bar graphs showing statistically significant effect of IFNY-ADSCS on growth of metastatic melanoma tumors. (Left) Quantification of proliferation and apoptosis was performed by averaging percentage of positively stained cells to total cells within 10 randomly selected areas at x200 magnification. IFNY-producing ADSCs significantly decreased the melanoma cell proliferation and increased tumor cell apoptosis in groups treated with IFNY-producing ADSCs in a statistically meaningful manner (ANOVA; $p<.001$ ). (Right) Quantification of angiogenesis was performed by counting the number of vessels in 10 randomly selected areas of CD31 stained sections at x200 magnification. Results indicate statistically significant inhibition of angiogenesis after injection of IFNY-ADSCs. Each group consisted of four mice. ${ }^{* *} P<.001$ (ANOVA). The statistical tests were two-sided. PDL1 = programmed cell death 1 ligand 1. 

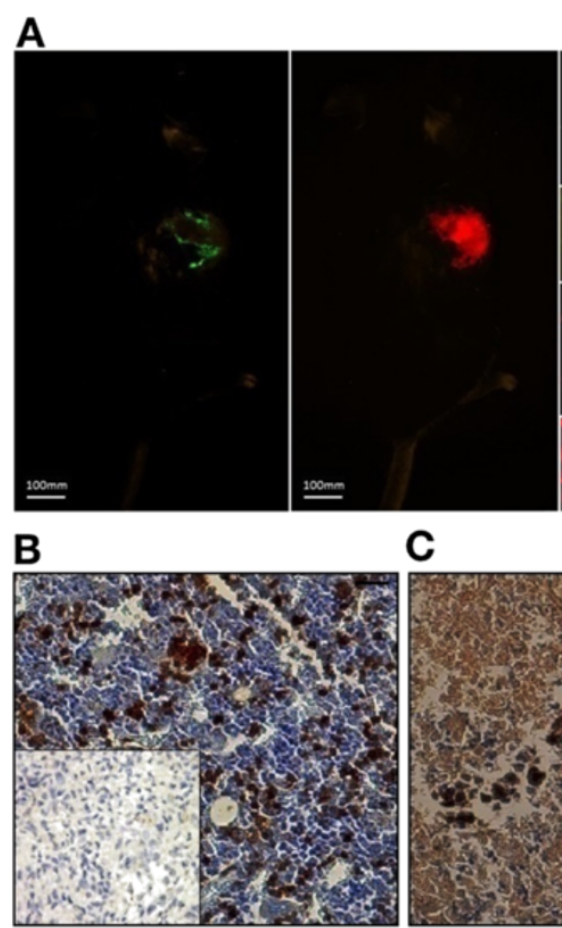

E

C
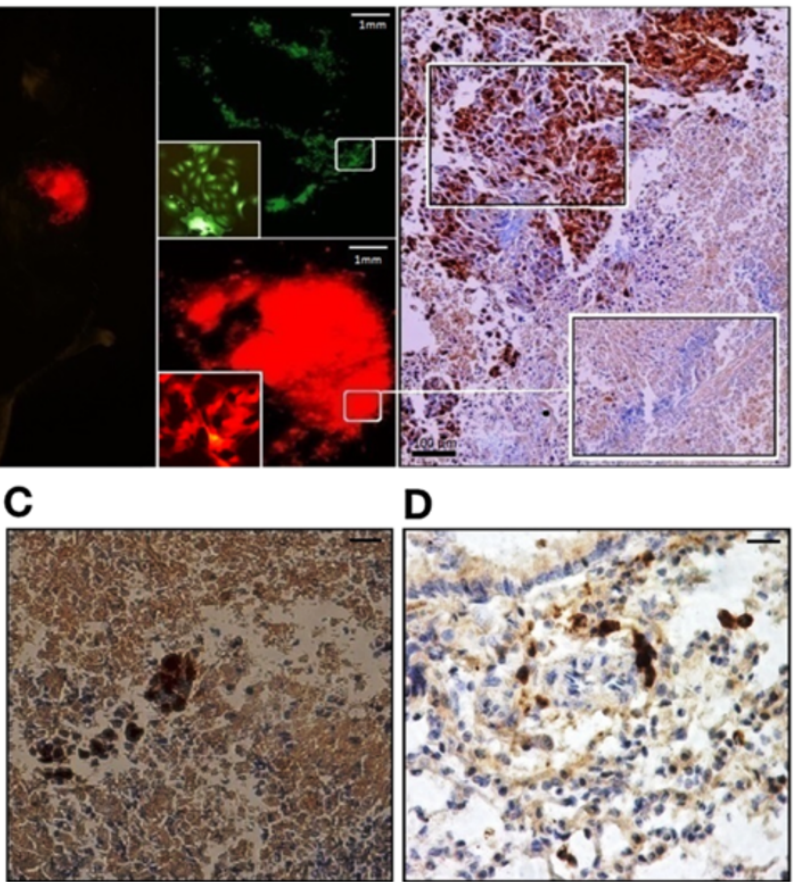

D

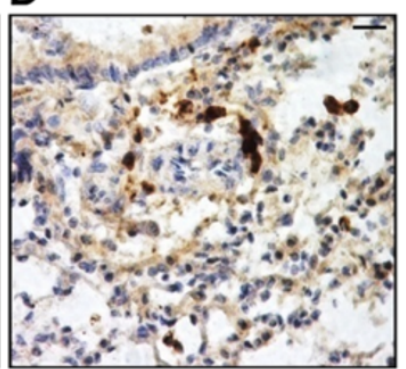

$\mathbf{F}$
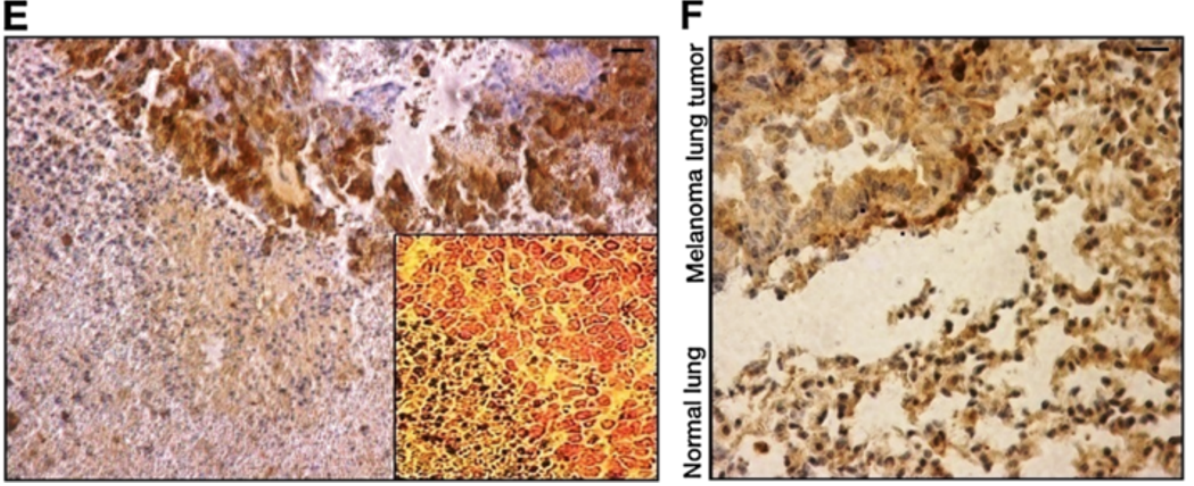

Figure 8 Homing analysis of ADSCs for EGFP and IFN $\gamma$ in subcutaneous tumor and lung metastatic models. A) Representative In vivo imaging of green and red fluorescence optical imaging in mouse with subcutaneously co-injected EGFP-ADSCs and RFP-melanoma cells. Focal imaging indicates aggregation of EGFP-expressing ADSCs around the melanoma cells in the tumor. IHC results of subcutaneous tumor sections for EGFP indicate that melanoma cells and ADSCs are not mixed completely in the tumor. B and C) IHC analysis of EGFP + cells. Scale bars =25 $\mu$ m. Panel $\mathbf{B}$ indicates a representative microscopic image of staining for a section of the bone marrow derived from an EGFP transgenic mouse as a positive control. Inlay shows a representative image of staining for a section of melanoma lung tumor from control group. Panel $\mathbf{C}$ shows a representative microscopic image of a melanoma lung tumor section after injection of EGFP-ADSCs. D, E, and F) IHC analysis of IFNy + cells. Panel D) demonstrates a representative microscopic image of a melanoma lung tumor section after injection of IFNY-ADSCs. Scale bar $=25 \mu \mathrm{m}$. Panel E) depicts a representative microscopic image of staining for a section of subcutaneous melanoma tumor which indicates juxtaposition of IFNY-ADSCs with melanoma cells. Scale bar $=50 \mu \mathrm{m}$. The Inlay shows representative image of TUNEL staining for IFNY-ADSC/melanoma mixed tumor samples which also confirm position of IFNY-ADSCS alongside the melanoma cells. Panel F) Representative image which demonstrates both melanoma lung tissue and normal lung tissue. The image indicates that most of IFNY-ADSCs homed into melanoma lung tissue rather than normal lung tissue. Scale bar $=50 \mu \mathrm{m}$.

$P=0.002$ for IFN $\gamma$-ADCS compared to normal mice, Figure 9E). Moreover, our results indicated that the population of Tregs in mice treated with IFN $\gamma$-ADCS $(P=0.109)$ and IFN $\gamma /$ TRAIL-ADSCs $(P=0.797)$ were comparable to the population of Tregs in normal mice. In contrast, the population of Tregs were increased significantly in a statistical manner in mice with established
B16F10 lung metastases, which were injected with PBS only, EGFP-ADSCs or TRAIL-ADSCs (ANOVA, $P<.001$, Figure 9E).

\section{Discussion}

In the present study, we demonstrated that $\varphi \mathrm{C} 31$ and/or $\mathrm{pB} t$ mediated non-viral gene transfer provides prolonged 

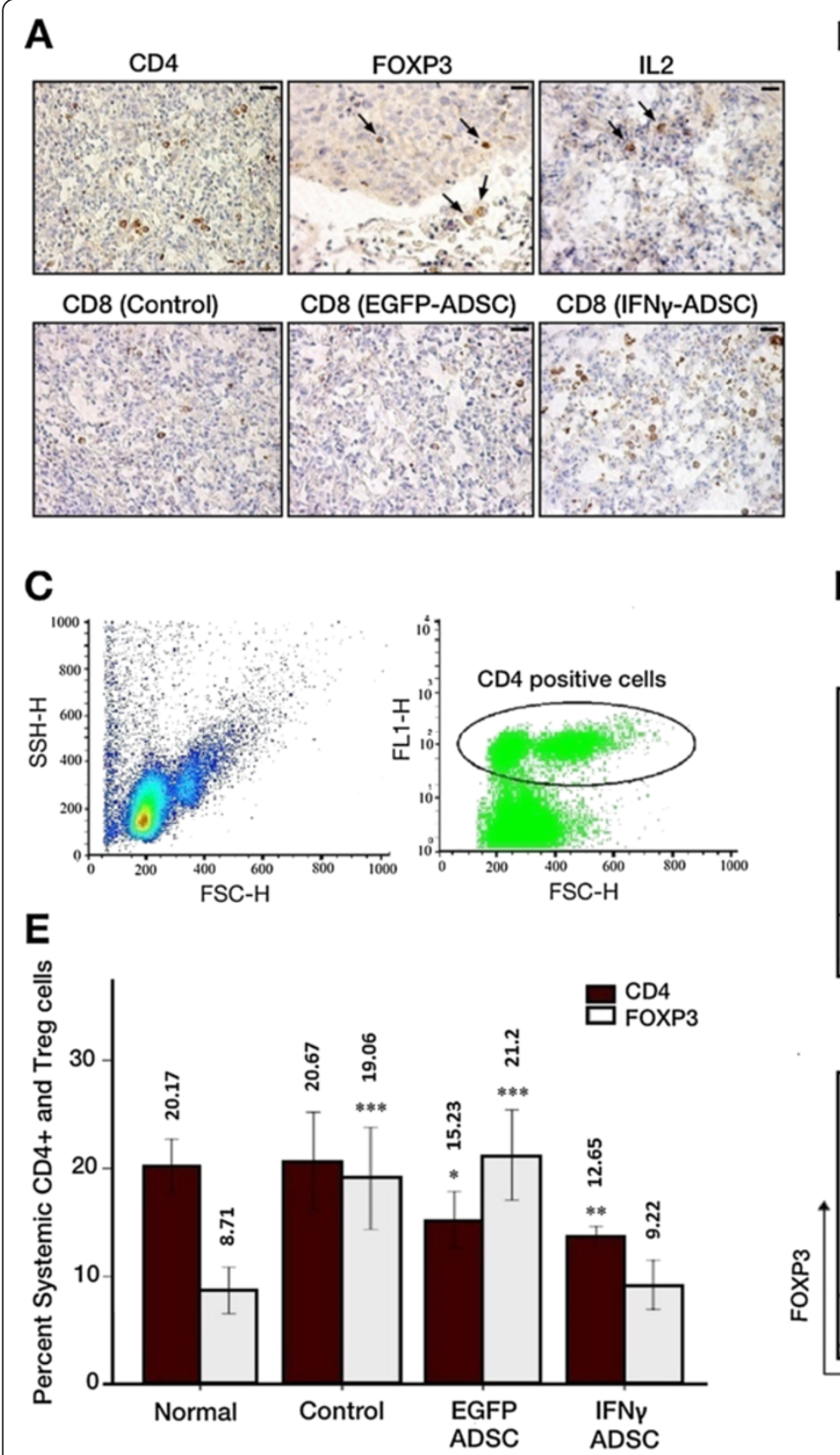

B

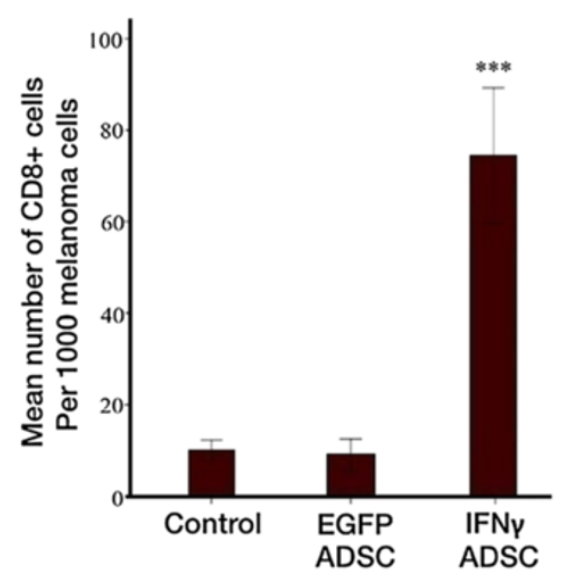

D

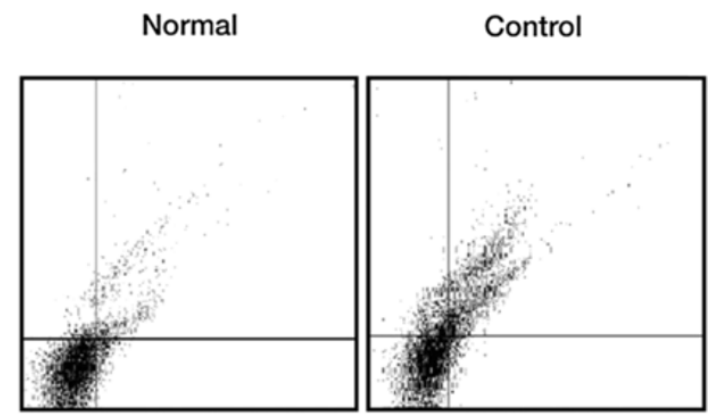

EGFP-ADSC

IFN $N^{-A D S C}$

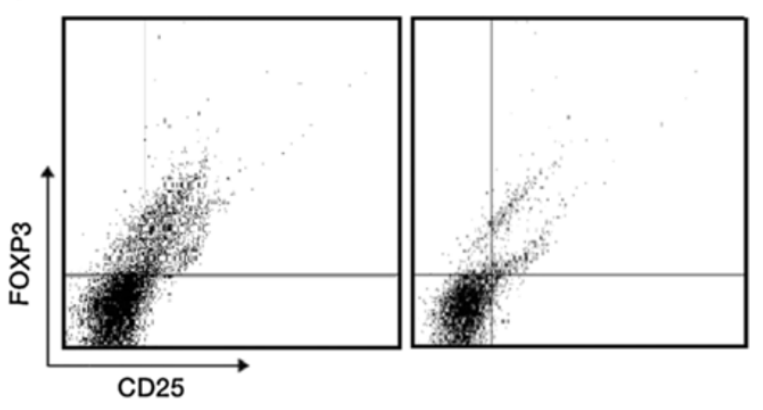

Figure 9 Determination of immune effectors following stem cell therapy. A) Infiltration of immune cells into the melanoma lung tumors. The lung tumors stained with monoclonal antibodies specific for mouse CD4, FOXP3, IL2 and CD8. Only respective images of CD4+, FOXP3+ and IL2+ cells from control samples are shown as there was no statistically significant difference between groups. Black arrows denote FOXP3+ and $112+$ cells. Results show significant infiltration of CD8+ cell into the melanoma lung tumors after injection of IFNy-expressing ADSCs. Scale bars =50 $\mu \mathrm{m}$. B) As shown in the bar graphs, mean number of CD8+ cells significantly increased in metastatic melanoma tumors of mice treated with IFNY-ADSCs in a statistically meaningful manner. $\mathbf{N}=6$; ${ }^{* * *} P<.001$. $\mathbf{C}$ and $\mathbf{D}$ ) Representative FACS plots for analysis of systemic CD4+ and regulatory $T$ cells in peripheral blood obtained from the sub-ocular region of mice with established melanoma metastases. In addition, blood samples were taken from normal mice to measure normal number of CD4+ and Tregs. C) Left plot is representative FACS plot showing two distinct populations of PBMCs: lymphocytes and monocytes. Right plot is representative FACS plot indicating CD4 positive PBMCs. D) CD4+ lymphocytes were analyzed for expression of CD25 and FOXP3 by flow cytometry. Representative plots indicating analysis of Tregs in Normal, Control, EGFP-ADSCs and IFNY-ADSCs. E) The percentage of CD4+ cells indicated a statistically significant decreased systemic level of CD4+ cells in ADSC-injected groups. The plot also shows a statistically significant decrease in the percentage of Tregs in the peripheral blood of mice with melanoma metastases treated with IFNY-producing ADSCs. This percentage is comparable with systemic regulatory T cells of normal mice $\left(P=.109\right.$; IFNY-ADSCs compared to normal mice). $N=6$; ${ }^{* * *} P<.001$, ${ }^{*} P<.01,{ }^{*} P<.05$. 
and high levels of transgene expression in ADSCs. Both the recombinase and the transposase systems worked well for modification of ADSCs. However, genomic modifications mediated by $\varphi \mathrm{C} 31$ may result in chromosomal rearrangements [21], whereas $\mathrm{pB} t$ is deactivated during the excision of the transposon from the helperindependent pmhyGENIE-3 construct [6]. We observed robust levels of IFNY and TRAIL expression in GMADSCs conferring upon them the ability to be efficiently used for cancer therapy. We also demonstrated that exogenously administered ADSCs survive and proliferate in the tumor environment. When co-injected with melanoma cells, ADSCs mostly stayed along with melanoma cells. We explored the effect of TRAIL-ADSCs and we showed that murine TRAIL, with a homology of $65 \%$ to human TRAIL is active on human CAOV-4 and Ej-138 cell lines [22]. However, certain tumor cells such as melanoma B16F10 and human MCF-7 breast cancer cell lines used in this study are not amenable to TRAILmediated apoptosis [23]. IFN $\gamma$ may sensitize cancer cells to TRAIL-induced apoptosis by upregulating Caspase- 8 through a Stat1/IRF1 dependent pathway [11-16]. Still, we did not observe sensitization of melanoma cells to TRAIL in the presence of IFN $\gamma$. Therefore, melanoma resistance is probably based upon lower expression of functional death receptors (DR1 and DR2) [24]. Actually, a recent study suggests the role of NFkB-mediated inflammatory signals through the death receptor DR5 which may promote malignant behaviors of melanoma cells [24]. Interestingly, the effect of IFNY on melanoma B16F10 cells was remarkable. IFN $\gamma$ has been clinically applied to treat a variety of malignancies [8]. Phase I trials of IFN $\gamma$ gene transfer into cancer cells in patients with metastatic melanoma have been performed, albeit with low therapeutic efficacy [25-27]. Furthermore, it has been shown that human IFN $\gamma$ produced by genetically modified MSCs was able to inhibit proliferation and induce apoptosis of human leukemia K562 cells in vitro [28]. We demonstrated that IFNY secreted by GMADSCs is able to directly affect melanoma cells in vitro, probably through activation of JAk1/Stat1 pathway [29]. Moreover, co-injection of IFN $\gamma$-ADSCs with melanoma cells reduced the growth of subcutaneous melanoma tumors. More importantly, intravenously injected IFN $\gamma$ ADSCs significantly reduced growth of pre-established melanoma lung metastases. In addition, systemic delivery of IFN $\gamma$-ADSCs does not elevate IFN $\gamma$ amounts in blood circulation, suggesting local expression of IFN $\gamma$. We also explored the anti-tumor effects of IFN $\gamma$ through the activation of the immune response [30]. We noted a significantly increased infiltration of CD8+ cells, while the CD4+ and IL2+ cell count in the tumor environment of IFN $\gamma$-ADSC treated mice remained constant. Additionally, we confirmed IFN $\gamma$-induced overexpression of
PD-L1 in melanoma tumor cells $[31,32]$. These observations suggest a possible role of PD-L1 in impairing T cell function because of; 1) the absence of infiltrated $\mathrm{T}$ helper 1 cells (no statistically significant difference in CD4+ and IL2+ cells) which is critical for the development of cell-mediated immune response [32], and 2) the accumulation of exhausted and inflamed CD8+ cells which failed to produce IL2. The latter could explain why melanoma metastases avoided complete eradication in spite of significant infiltration of CD8+ cells [33]. Actually, CD8+ T cells and IFN $\gamma$ may induce the expression of indoleamine-2,3-dioxygenase (IDO) and PD-L1 in the melanoma tumor microenvironment, and inhibit the activation of additional $\mathrm{T}$ cells trafficking [34]. Therefore, we hypothesize that the observed anti-tumor effect was primarily due to apoptosis in the melanoma tumor and tumor endothelial cells. A similar observation has been reported by Kakuta et al., where they examined effects of IFNY receptor-deficiency and NK cell depletion on the melanoma tumor growth and suggested that IFN $\gamma$ prevents the murine melanoma metastases by directly inhibiting cell growth when the tumor mass is small and in an earlier developmental stage [35]. It is also noteworthy that the population of infiltrated FOXP3+ cells in IFN $\gamma$-ADSC treated mice did not differ to those in mice of other treatment groups, indicating that the higher systemic Tregs (in control and EGFPADSC injected mice) was possibly due to immunosuppression mediated by tumor progression [36]. Therefore, intravenous injection of IFN $\gamma$-ADSC indirectly maintained normal levels of systemic Treg through inhibition of melanoma growth [36]. However, systemic injection of GM-ADSCs showed immunosuppressive properties probably associated with PD-L1 expression by ADSCs [37]. The selective blockage of PD-L1 may be a potential strategy to improve the therapeutic value of IFN $\gamma$ producing ADSCs for melanoma treatment [38].

We were able to show that systematically transplanted ADSCs engrafted into tumor cells, however the fact that stem cells also migrate to many other organs makes it difficult to trace them. In fact, there is no clear consensus amongst researchers where else such treated stem cells end up after injection [39]. It is well known that systemically infused MSCs typically become trapped within the lungs as the first micro capillary network they encounter (pulmonary "first-pass" effect) [40]. Within 24h MSCs migrate to other organs, in particular the liver and also the spleen $[41,42]$. Consecutively, MSCs appear at injured tissue sites and tumors as well as bone marrow, liver and spleen $[43,44]$. This redistribution attributes to the observed reduction of MSCs present in the lungs, as does cell death [45]. Kidd et al. showed that in addition to the specific tropism of MSCs in tumor sites, some MSCs remained in the lungs, as well as some disseminating into 
the liver [46]. An alternate study showed that few days after tail vein stem cell injections, cells dissipated from the animals and were undetectable within one week after injection [47].

Studies have attempted to address the eventual fate of the MSCs within tumor microenvironments. MSC may differentiate towards tumor-associated fibroblast (TAF) phenotypes [48]. In addition, MSCs may acquire endothelial-like characteristics, but their involvement in vasculogenesis is complex. Comşa et al. indicated that MSCs, negative for CD31, have a clear tendency to form capillary-like structures in the presence of tumor-derived VEGF [49]. The same proved true in our hands where ADSCs co-injected with melanoma cells organized into capillary-like structures, whereas, they did not differentiate into three mesodermal lineages in the melanoma tumor environment.

In order to translate stem cell-based anticancer strategies into clinical therapy, it is essential to identify and minimize treatment-associated risks. Only with improvements in safety, quality, and efficiency of stem cell/gene therapy for inoperable or malignant tumors, clinical scenarios can be envisaged. For the first time we employed DNA integrating vectors including PhiC31and PiggyBac transposase systems for safe and stable modification of MSCs. We modified ADSCs to produce IFNY and TRAIL. Then evaluated antitumor effects of cytokineproducing GM-ADSCs in murine models of melanoma. The present study is the first in vivo attempt to use ADSCs as a vehicle for IFN $\gamma$-mediated immunotherapy and demonstrates the potential of non-virally modified IFN $\gamma$-ADSCs for melanoma cancer therapy. This may have a significant role in the management of cancer in the future.

\section{Materials and methods}

\section{Isolation of ADSCs and culture}

ADSCs were isolated from inguinal fat pads of 4-5 weekold male C57BL6 mice ( $\mathrm{N}=8 ; 21.5 \pm 0.7$ g body weight). Isolated cells were grown in culture medium $(\mathrm{CM})$ consisting of Dulbecco's modified Eagle's medium (DMEM; Invitrogen Carlsbad, CA), 10\% Fetal bovine serum (FBS; Invitrogen Carlsbad, CA), $1 \mathrm{~g} / \mathrm{L}$ glucose, $1 \%$ L-glutamine, and 1\% penicillin-streptomycin (Invitrogen Carlsbad, CA). For details please see Additional file 1.

\section{ADSCs differentiation}

ADSCs cultured at passage 6 were used for adipogenic, osteogenic, and chondrogenic differentiation. As a first step, cells were cultured for 3 weeks in differentiation medium and consecutively stained with Oil red O, Alizarin red S, Von Kossa S, Alcian blue, and Toluidine blue. For a detailed description of the experiments please see Additional file 1.

\section{Immunotyping of ADSCs}

Immunotyping of surface markers was performed in passage 6 with BD Calibur" (Becton Dickinson San Jose, CA) using monoclonal antibodies against mouse CD11b, CD24, CD34, CD45, CD73, CD90.1, CD105, CD133, CD146, CD309 and CXCR4 (all form eBioscience, San Diego, CA). A total of $5 \times 10^{5}$ cells from passage 6 were incubated with each antibody $(\mathrm{Ab})$ in PBS with $3 \%$ bovine serum albumin (BSA; Sigma, St. Louis, MO) for $40 \mathrm{~min}$ at $4^{\circ} \mathrm{C}$. The Cells were then washed with $\mathrm{PBS}$ and fixed with $\mathrm{BD}$ fixation reagent (BD Biosciences, San Jose, CA sciences). Analysis of the FACS data was carried out with a FlowJo software version 10 (Treestar, OR).

\section{Vector construction}

Plasmids pCAG-DsReds [21], pCMVInt [6], pDRBB2 [50], pBEB [6], pISRE-TA-Luc (Clontech, Mountain View, CA), pBLB [6], pmhyGENIE-3 [51], coding sequences (CDS) of murine full-length IFN $\gamma$, TRAIL and the sequence of SV40 Promoter were used in this study. The plasmid $\mathrm{pBEB}$ (carrying the attB, the enhanced green fluorescent protein [EGFP] reporter gene) and the vector pmhyGENIE-3 (containing EGFP gene, a hyperactive self inactivating piggyBac sequence and piggyBac transposon) were used as a control plasmids for integrase and transposase systems. We prepared the vector pDsRed-attb-zeo (carrying eRFP, attB, eukaryotic zeocin resistance gene) using the plasmid pCAG-DsReds (expressing the Red fluorescent protein [eRFP] reporter gene), the plasmid pDRBB2 (carrying $a t t B$ and antibiotic resistance gene for zeocin under the prokaryotic $\mathrm{T} 7$ promoter) and a synthesized sequence of $\mathrm{T} 7$ promoter. The vector pBTB (carrying attB and antibiotic resistance gene for G418 and a murine fulllength TRAIL) was prepared using the vector pBLB (carrying the $a t t B$ and firefly luciferase [FL] under a chicken beta actin and rabbit beta globin intron [CAG] promoter) and synthesized murine TRAIL coding sequence (CDS; protein ID = NP_033451.1). The plasmid pISRE-TA-LucattB was prepared using the vector pISRE-TA-Luc (carrying FL gene located downstream of ISRE enhancer element and a minimal TA promoter; Clontech, Palo Alto CA) and pBLB. All integrase-related constructs were cotransfected with the plasmid pCMVInt (producing $\varphi \mathrm{C} 31$ integrase) to achieve stable cell modification. Plasmids pDsRed-attb-zeo, pmhyGENIE-3 and the coding sequence of the full-length murine IFNY (protein ID = NP_032363.1) were used for construction of pmhyGENIE-3-IFN $\gamma$. CDS of murine full-length IFN $\gamma$, TRAIL and the sequence of SV40 Promoter with pertinent restriction sites were synthesized by Generay Biotech (Co., Ltd). All vectors were purified by EndoFree ${ }^{\circ}$ plasmid maxi kit (Qiagen, Valencia, CA) before transfection. For additional information on vector construction please see Additional file 1. 


\section{Murine ADSCs transfection, selection, and transgene expression}

Nucleofection was perfomed by nucleofector device $2 b$ (Amaxa Biosystems) using the Human MSC Nucleofector kit (Amaxa Biosystems) with program X-001 (mouse T cells). About $2 \mu \mathrm{g}$ of DNA plasmid and $5 \times 10^{5}$ ADSCs were used for each nucleofection experiment and done in triplicate for each plasmid construct. The vector pMAX was utilized for evaluation of nucleofection efficiency. ADSCs modified with pBEB/pCMVInt, pBIB/pCMVInt, pmhyGENIE-3, and pmhyGENIE-3-IFN $\gamma$ are referred to as EGFP/Int-ADSC, TRAIL-ADSC, EGFP-ADSC and IFN $\gamma-$ ADSC respectively. TRAIL-ADSCs were modified with pmhyGENIE-3-IFN $\gamma$ to generate ADSCs co-expressing TRAIL and IFN $\gamma$ (referred as IFN $\gamma /$ TRAIL-ADSC). After each nucleofection, $500 \mu \mathrm{l}$ of $\mathrm{CM}$ was added to each nucleofector cuvette and cells were seeded into 6 well plates at $37^{\circ} \mathrm{C}$ in $5 \% \mathrm{CO}_{2}$. Forty eight hours after each nucleofection, selection with related resistant antibiotic was initiated. ADSCs co-nucleofected with the vectors pBEB/pCMVInt (EGFP/Int-ADSC) and pBTB/pCMVInt (TRAIL-ADSC) were exposed to $1000 \mu \mathrm{g} / \mathrm{mL}$ of G418 sulfate (Roche, Indianapolis, IA) for two weeks and maintained in CM with $800 \mu \mathrm{g} / \mathrm{mL}$ of G418 sulfate. ADSCs nucleofected with the plasmids pmhyGENIE-3 (GFP-ADSC) and pmhyGENIE-3IFN $\gamma$ (IFN $\gamma$-ADSC) were selected with $200 \mu \mathrm{g} / \mathrm{mL}$ of hygromycin (Roche, Indianapolis, IA) for about 10 days and maintained under selection pressure with $100 \mu \mathrm{g} / \mathrm{mL}$ of hygromycin, giving rise to EGFP-ADSCs and IFN $\gamma$-ADSCs. After about 2 weeks $15 \times 10^{4}$ of TRAIL-ADSCs were nucleofected with pmhyGENIE-3-IFN $\gamma$ and selected with hygromycin to create TRAIL/IFN $\gamma$ co-expressing ADSCs (TRAIL/IFN $\gamma$-ADSCs). These cells were maintained in a CM containing G418 (800 $\mu \mathrm{g} / \mathrm{mL})$ and hygromycin $(100 \mu \mathrm{g} / \mathrm{mL})$. Surface and intracellular staining of TRAILADSCs and EGFP/Int-ADSC (control) were done with anti-TRAIL Ab (eBioscience, San Diego, CA). Expression of IFN $\gamma$ was confirmed by Western blot. Protein extraction was performed by lysing EGFP-ADSCs and IFN $\gamma$-ADSCs with Cell lysis buffer (Sigma, St. Louis, MO) supplemented with a protease inhibitor cocktail $(100 \mu \mathrm{g} / \mathrm{mL}$; Sigma, St. Louis, MO). Proteins were separated in 12\% SDS PAGE and transferred to nitrocellulose membrane (Amersham Biosciences/GE Healthcare, Pittsburgh, PA). The membrane was blocked in buffer containing PBS, $10 \%$ powdered nonfat milk (Sigma, St. Louis, MO), and 0.05\% Tween-20 (Sigma, St. Louis, MO). Blotting was performed with a monoclonal rabbit anti-mouse IFNy $\mathrm{Ab}$ at dilution of 1:1000. After twice washing the membrane with blocking buffer, blotting continued using a horseradish peroxidase (HRP)-conjugated anti-rabbit secondary antibody at 1:1000 dilution (Abcam, Cambridge, MA). Interferon $-\gamma$ protein band was detected after adding the enhanced chemiluminescence reagent (Amersham Biosciences/GE Healthcare,
Little Chalfont) by an imaging system (Bruker Inc, Ettlingen, Germany) using UV-Epi-Illumination source with $30 \mathrm{sec}-$ onds of exposure time.

\section{Cancer cell culture, transfection, and selection}

The mouse melanoma cell line B16F10, human breast cancer cell line MCF-7, human bladder carcinoma derived cell line Ej-138, and human ovarian carcinoma cell line CAOV-4 were purchased from the Pasteur institute of Iran. Cancer cells were maintained in $\mathrm{CM}$ at $37^{\circ} \mathrm{C}$ in a $5 \%$ $\mathrm{CO}_{2}$ atmosphere. In this study, melanoma cells which were modified with $\mathrm{pBEB} / \mathrm{pCMVInt}$ and pDsRed-attbzeo/pCMVInt vectors are referred to GFP-melanoma and RFP-melanoma cells respectively. Lipofection was used for modification of melanoma cells. To create transgenic melanoma B16F10, cells at a density of $2 \times 10^{5}$ per well in triplicate for each group were seeded in 6-well plates. After $24 \mathrm{~h}$, cells were co-transfected with the vector pBEB/pCMVInt, pBLB/pCMVInt, pISRE-TA-LUC-attb/ pCMVInt, and pDsRed-attb-zeo/pCMVInt using lipofectamine $2000^{\mathrm{mt}}$ transfection reagent (Invitrogen, Carlsbad, CA) according to the manufacturer's instructions. EGFPmelanoma, FL-melanoma and ISRE/FL-melanoma were selected, and maintained with $1000 \mu \mathrm{g} / \mathrm{mL}$ of G418. RFPmelanoma was exposed to $400 \mu \mathrm{g} / \mathrm{mL}$ zeocin (Invitrogen, Carlsbad, CA) and after about two weeks maintained in $\mathrm{CM}$ with $100 \mu \mathrm{g} / \mathrm{mL}$ of zeocin.

\section{Bioactivity of IFN $\gamma$ and TRAIL produced by ADSCs}

To study the effect of IFN $\gamma$-ADSC and TRAIL-ADSC on melanoma B16F10 cells we evaluated proliferation and apoptosis by MTT (Sigma, St. Louis, MO) and Annexin $\mathrm{V}$ apoptosis (Roche, Indianapolis, IA) assays. MTT and Annexin $\mathrm{V}$ apoptosis assays were performed as explained in Additional file 1.

\section{Monitoring the induction of the STAT1/2 components of Jak/STAT-mediated signal transduction pathways}

FL-melanoma and ISRE/FL-melanoma cells were seeded into 12 well plates and incubated at $37^{\circ} \mathrm{C}$ in $5 \% \mathrm{CO}_{2}$. Supernatants from either EGFP-ADSCs or IFN $\gamma$-ADSCs were added to these cells once they reached cell densities of $10^{5}$ and $3 \times 10^{5}$ respectively. Two days later, a volume of ONE-Glo ${ }^{\mathrm{Tn}}$ luciferase assay reagent (Promega Corp. Madison, WI) equal to that of the CM was added to each well and samples were mixed thoroughly. Luminescence imaging was performed in an imaging system (Bruker Inc, Ettlingen, Germany) using a UV-EpiIllumination source with a $15 \mathrm{~min}$ exposure time.

\section{In vivo studies and optical imaging}

Eight-week-old male C57BL/6 mice (30.1 $\pm 0.6 \mathrm{~g}$ body weight) were purchased from the Pasteur institute of Iran. Handling of the animals was performed according 
to the guidelines of the Institutional Animal Care and Ethics Committee of Isfahan University. For the subcutaneous models of melanoma, $2 \times 10^{6}$ RFP-melanoma cells were delivered either alone or concurrently with $7.5 \times 10^{5}$ ADSCs of each group described above, in $200 \mu \mathrm{l}$ of PBS into the right flank of the mice. The day of melanoma injection was defined as day 0 . At day 21, in vivo red fluorescence optical imaging of subcutaneous RFP-melanoma bearing mice was performed. Subsequently, all mice were euthanized via pentobarbital overdose. In lung metastatic models, $7.5 \times$ $10^{5}$ RFP-melanoma cells were delivered into the lateral tail vein of twelve mice per group. Ten days later, the mice received 7.5 $\times 10^{5}$ of GM-ADSC in a volume of $200 \mu$ of PBS solution (control group received only $200 \mu \mathrm{l}$ of PBS) by tail vein injection. Six mice from each group were sacrificed with pentobarbital overdose at day-28. Subsequently, their lungs were dissected and ex vivo red fluorescence optical imaging of lung samples was performed. The six remaining mice from each group were kept alive for long-term survival analysis. For imaging, animals were anesthetized with $2 \%$ isoflurane and images were captured using a multiwavelength source with a 2 min exposure time in the InVivo F Pro small-animal imaging system (Bruker Inc, Ettlingen, Germany).

\section{Serum levels of IFNY}

Frozen serum collected from blood samples at days 10, 16, and 21 was used in triplicate to quantify IFNy protein levels by enzyme-linked immunosorbent assay (ELISA) using the mouse IFNY Elipair kit (Abcam, Cambridge, $\mathrm{MA}$ ) in accordance with the manufacturer's protocol. Samples were analyzed at an absorbance of $450 \mathrm{~nm}$ with minimal sensitivity of $15 \mathrm{pg} / \mathrm{mL}$ for IFN $\gamma$ detection.

\section{Analysis of systemic $\mathrm{CD} 4+$ and $\mathrm{CD} 4^{+} \mathrm{CD}_{25}{ }^{+} \mathrm{FOXP3}^{+}$ regulatory $\mathrm{T}$ cells (Treg)}

Peripheral blood was taken from sub-ocular regions of normal C57BL/6 mice (control samples) and lung metastatic melanoma bearing mice at day 28 post melanoma cell injection. Blood was overlaid onto $3 \mathrm{~mL}$ of Ficoll-Paque and after centrifuging at $1800 \mathrm{rpm}$ for 15 minutes, peripheral blood mononuclear cells (PBMCs) at the interface were collected. PBMCs were washed twice in PBS and then Treg cells were analyzed using a mouse Treg detection kit (Miltenyi Biotec, Auburn, CA). PBMCs were stained with FITC-conjugated monoclonal anti-mouse $\mathrm{CD} 4 \mathrm{Ab}$ and $\mathrm{APC}$-conjugated monoclonal anti-mouse $\mathrm{CD} 25 \mathrm{Ab}$ for 30 minutes at $4^{\circ} \mathrm{C}$ in the dark. Subsequently, the PBMCs were incubated with a PE-conjugated monoclonal anti-mouse Foxp3 Ab, following the staining protocol provided by Miltenyi Biotec. FACS data analysis was performed with BD CellQuest Pro or FlowJo software.

\section{Histological analysis}

Tissue sections were used for differentiation staining, terminal deoxynucleotidyl transferase-mediated dUTP-biotin nick end labeling (TUNEL) staining and immunohistochemistry (IHC) analysis. IHC was performed for EGFP, Ki67, murine IFN $\gamma$, murine IL2, programmed cell death 1 ligand 1 (PD-L1; B7-H1), CD31, CD4+, CD8+ and FOXP3+. For a detailed description of the experiments please see Additional file 1.

\section{Statistical analysis}

Statistical analysis was performed using SPSS version 19 (SPSS Inc, Chicago, IL). The statistical differences between the groups were assessed by Student $t$ test, ANOVA, and log-rank tests. Survival was defined as the date of melanoma cell injection to the date of death. $P$ values less than .05 were considered statistically significant. All statistical tests were two-sided. Data are presented as mean values with $95 \%$ confidence intervals (CIs).

\section{Additional files}

\begin{abstract}
Additional file 1: Supplementary data: Supplementary Methods, Reference and Tables (Table S1, Table S2 and Table S3).

Additional file 2: Figure S1. Differentiation analysis of melanoma tissues. Mouse fat tissue from the inguinal fat pad, murine cartilage isolated from patellae and mouse bone tissue obtained from a 8 week-old male C57BL6 mouse were used as positive controls (Left panels). Representative images from melanoma/IFNY-ADSCs co-injected groups are shown (Right panels). Results indicated there was no in vivo differentiation of ADSCs from different groups into three mesodermal lineages. Scale bars $=50 \mu \mathrm{m}$. A) Oil red O staining. B) Alician blue staining. C) Alizarin red staining. ADSC = adipose derived mesenchymal stem cell, IFNY = interferon gamma

Additional file 3: Figure S2. Formation of capillary-like structures by ADSCs in ADSCs/Melanoma co-injected groups. A) Representative microscopic images of immunohistochemistry (IHC) staining for EGFP. (Left) Melanoma/PBS (Right) Melanoma/EGFP. Capillary-like structures are formed by EGFP expressing ADSCs. B) Representative microscopic images of IHC staining for PD-L1. (Left) Melanoma/PBS (Right) Melanoma/ EGFP. Mesenchymal stem cells highly expressing PD-L1 have organized capillary-like structures.
\end{abstract}

\section{Competing interests}

The authors declare that they have no competing interests.

\section{Authors' contributions}

VB participated in the conception of the study, designed and carried out the experiments, analyzed the data and drafted the manuscript. NA helped in the collection interpretation of the data. SM provided reagents, helped on concepts of the study, analysis of data and edited the manuscript. JU helped in the analysis and interpretation of the data, participated in editing the manuscript. RS participated in the collection and assembly of data and provided administrative support. SHJ conceived and designed the study; participated in the analysis and interpretation of data and drafting of the manuscript. All authors read and approved the final manuscript.

\section{Acknowledgments}

This research was supported by grant 189048 from Isfahan University of Medical Sciences. The sponsor had no role in the design of the study; the collection, analysis, and interpretation of the data; the writing of the article and the decision to submit the article for publication. We would like to thank Dr Michele Pamela Calos at Stanford University for generously 
providing the plasmids $\mathrm{pBEB}, \mathrm{pBLB}, \mathrm{pCMVInt}$, and pDrBB2 and Dr Constance Cepko at Harvard Medical School for kind gift of the plasmid pCAG-DsReds. We thank Dr Yousef Gheisari and Dr Mohammad Ali Daneshmand for skillful technical assistance with immunohistochemistry.

\section{Author details}

${ }^{1}$ Applied Physiology Research Center, Isfahan University of Medical Sciences, Isfahan, Iran. ${ }^{2}$ Department of Genetics and Molecular Biology, School of Medicine, Isfahan University of Medical Sciences, Isfahan, Iran. ${ }^{3}$ Department of Anatomy, Biochemistry, and Physiology, John A Burns School of Medicine, University of Hawaii, Honolulu, HI 96819, USA. ${ }^{4}$ Manoa BioSciences, Honolulu, HI 96819, USA. ${ }^{5}$ Department of Physiology, Applied Physiology Research Center, School of Medicine, Isfahan University of Medical Sciences, Isfahan, Iran

Received: 8 August 2014 Accepted: 14 November 2014 Published: 26 November 2014

\section{References}

1. Studeny M, Marini FC, Champlin RE, Zompetta C, Fidler IJ, Andreeff M: Bone marrow-derived mesenchymal stem cells as vehicles for interferon-beta delivery into tumors. Cancer Res 2002, 62(13):3603-3608.

2. Keravala A, Ormerod BK, Palmer TD, Calos MP: Long-term transgene expression in mouse neural progenitor cells modified with phiC31 integrase. J Neurosci Methods 2008, 173(2):299-305.

3. Hackett PB: Integrating DNA, vectors for gene therapy. Mol Ther 2007, 15(1):2-10.

4. Hollis RP, Stoll SM, Sclimenti CR, Lin J, Chen-Tsai Y, Calos MP: Phage integrases for the construction and manipulation of transgenic mammals. Reprod Biol Endocrinol 2003, 1:79.

5. Wu SC, Meir YJ, Coates CJ, Handler AM, Pleczar P, Moisyadi S, Kaminski JM: PiggyBac is a flexible and highly active transposon as compared to sleeping beauty, Tol2, and Mos1 in mammalian cells. Proc Natl Acad Sci U S A 2006, 103(41):15008-15013.

6. Urschitz J, Kawasumi M, Owens J, Morozumi K, Yamashiro H, Stoytchev I, Marh J, Dee JA, Kawamoto K, Coates CJ, Kaminski JM, Pelczar P, Yanagimachi R, Moisyadi S: Helper-independent piggyBac plasmids for gene delivery approaches: strategies for avoiding potential genotoxic effects. Proc Natl Acad Sci U S A 2010, 107(18):8117-8122.

7. Ikeda H, Old $\mathrm{L}$, Schreiber RD: The roles of IFN gamma in protection against tumor development and cancer immunoediting. Cytokine Growth Factor Rev 2002, 13(2):95-109.

8. Jonasch E, Haluska FG: Interferon in oncological practice: review of interferon biology, clinical applications, and toxicities. Oncologist 2001, 6(1):34-55.

9. Park SY, Seol JW, Lee YJ, Cho JH, Kang HS, Kim IS, Park SH, Kim TH, Yim JH, Kim M, Billiar TR, Seol DW: IFN-gamma enhances TRAlL-induced apoptosis through IRF-1. Eur J Biochem 2004, 271(21):4222-4228.

10. Grisendi G, Bussolari R, Cafarelli L, Petak I, Rasini V, Veronesi E, De Santis G, Spano C, Tagliazzucchi M, Barti-Juhasz H, Scarabelli L, Bambi F, Frassoldati A, Rossi G, Casali C, Morandi U, Horwitz EM, Paolucci P, Conte P, Dominici M: Adipose-derived mesenchymal stem cells as stable source of tumor necrosis factor-related apoptosis-inducing ligand delivery for cancer therapy. Cancer Res 2010, 70(9):3718-3729.

11. Fulda S, Debatin KM: IFNgamma sensitizes for apoptosis by upregulating caspase-8 expression through the Stat1 pathway. Oncogene 2002, 21(15):2295-2308

12. Lissat $\mathrm{A}$, Vraetz $\mathrm{T}$, Tsokos $\mathrm{M}$, Klein $\mathrm{R}$, Braun $\mathrm{M}$, Koutelia N, Fisch P, Romero ME, Long L, Noellke P, Mackall CL, Niemeyer CM, Kontny U: Interferongamma sensitizes resistant Ewing's sarcoma cells to tumor necrosis factor apoptosis-inducing ligand-induced apoptosis by up-regulation of caspase-8 without altering chemosensitivity. Am J Pathol 2007, 170(6):1917-1930

13. Yang $X$, Merchant MS, Romero ME, Tsokos M, Wexler LH, Kontny $U$, Mackall CL, Thiele CJ: Induction of caspase 8 by interferon gamma renders some neuroblastoma (NB) cells sensitive to tumor necrosis factor-related apoptosis-inducing ligand (TRAIL) but reveals that a lack of membrane TR1/TR2 also contributes to TRAIL resistance in NB. Cancer Res 2003, 63(5):1122-1129.

14. Langaas V, Shahzidi S, Johnsen JI, Smedsrod B, Sveinbjornsson B: Interferongamma modulates TRAIL-mediated apoptosis in human colon carcinoma cells. Anticancer Res 2001, 21(6):3733-3738.
15. Lee J, Shin JS, Choi IH: Human brain astrocytes mediate TRAIL-mediated apoptosis after treatment with IFN-gamma. Yonsei Med J 2006, 47(3):354-358.

16. Johnsen Jl, Pettersen I, Ponthan F, Sveinbjornsson B, Flaegstad T, Kogner P: Synergistic induction of apoptosis in neuroblastoma cells using a combination of cytostatic drugs with interferon-gamma and TRAIL. Int $J$ Oncol 2004, 25(6):1849-1857.

17. Zeytin H, Reali E, Zaharoff DA, Rogers CJ, Schlom J, Greiner JW: Targeted delivery of murine IFN-gamma using a recombinant fowlpox virus: NK cell recruitment to regional lymph nodes and priming of tumor-specific host immunity. J Interferon Cytokine Res 2008, 28(2):73-87.

18. Elzaouk L, Moelling K, Pavlovic J: Anti-tumor activity of mesenchymal stem cells producing IL-12 in a mouse melanoma model. Exp Dermatol 2006, 15(11):865-874.

19. Kucerova L, Matuskova M, Pastorakova A, Tyciakova S, Jakubikova J, Bohovic $\mathrm{R}$, Altanerova V, Altaner C: Cytosine deaminase expressing human mesenchymal stem cells mediated tumour regression in melanoma bearing mice. J Gene Med 2008, 10(10):1071-1082.

20. Ren C, Kumar S, Chanda D, Chen J, Mountz JD, Ponnazhagan S: Therapeutic potential of mesenchymal stem cells producing interferonalpha in a mouse melanoma lung metastasis model. Stem Cells 2008, 26(9):2332-2338.

21. Liu J, Jeppesen I, Nielsen K, Jensen TG: Phic31 integrase induces chromosomal aberrations in primary human fibroblasts. Gene Ther 2006 , 13(15):1188-1190.

22. Wiley SR, Schooley K, Smolak PJ, Din WS, Huang CP, Nicholl JK, Sutherland GR, Smith TD, Rauch C, Smith CA, Goodwin RG: Identification and characterization of a new member of the TNF family that induces apoptosis. Immunity 1995, 3(6):673-682.

23. Igney FH, Krammer PH: Immune escape of tumors: apoptosis resistance and tumor counterattack. 2002;71(6):907-20. 26. J Leukoc Biol 2002, 71(6):907-920.

24. Takahashi K, Takeda K, Saiki I, Irimura T, Hayakawa Y: Functional roles of TRAIL-DR5 interaction in B16F10 by activating NFkappaB pathway to induce metastatic potential. Cancer Sci 2013, 104(5):558-562.

25. Abdel-Wahab Z, Weltz C, Hester D, Pickett N, Vervaert C, Barber JR, Jolly D, Seigler HF: A phase I clinical trial of immunotherapy with interferongamma gene-modified autologous melanoma cells: monitoring the humoral immune response. Cancer 1997, 80(3):401-412.

26. Nemunaitis J, Bohart C, Fong T, Meyer W, Edelman G, Paulson RS, Orr D, Jain V, O'Brien J, Kuhn J, Kowal K, Burkeholder S, Bruce J, Ognoskie N, Wynne D, Martineau D, Ando D: Phase I trial of retroviral vector-mediated interferon (IFN)-gamma gene transfer into autologous tumor cells in patients with metastatic melanoma. Cancer Gene Ther 1998, 5(5):292-300.

27. Nemunaitis J, Fong T, Robbins JM, Edelman G, Edwards W, Paulson RS, Bruce J, Ognoskie N, Wynne D, Pike M, Kowal K, Merritt J, Ando D: Phase I trial of interferon-gamma (IFN-gamma) retroviral vector administered intratumorally to patients with metastatic melanoma. Cancer Gene Ther 1999, 6(4):322-330.

28. Li X, Lu Y, Huang W, Xu H, Chen X, Geng Q, Fan H, Tan Y, Xue G, Jiang X: In vitro effect of adenovirus-mediated human gamma interferon gene transfer into human mesenchymal stem cells for chronic myelogenous leukemia. Hematol Oncol 2006, 24(3):151-158.

29. Schmitt MJ, Philippidou D, Reinsbach SE, Margue C, Wienecke-Baldacchino A, Nashan D, Behrmann I, Kreis S: Interferon-gamma-induced activation of Signal Transducer and Activator of Transcription 1 (STAT1) up-regulates the tumor suppressing microRNA-29 family in melanoma cells. Cell Commun Signal 2012, 10(1):41.

30. Beatty GL, Paterson Y: Regulation of tumor growth by IFN-gamma in cancer immunotherapy. Immunol Res 2001, 24(2):201-10.

31. Jin HT, Ahmed R, Okazaki T: Role of PD-1 in regulating T-cell immunity. Curr Top Microbiol Immunol 2011, 350(6):17-37.

32. Yang W, Chen PW, Li H, Alizadeh H, Niederkorn JY: PD-L1: PD-1 interaction contributes to the functional suppression of T-cell responses to human uveal melanoma cells in vitro. Invest Ophthalmol Vis Sci 2008, 49(6):2518-2525.

33. Sakuishi $K$, Apetoh L, Sullivan JM, Blazar BR, Kuchroo VK, Anderson AC: Targeting Tim-3 and PD-1 pathways to reverse T cell exhaustion and restore anti-tumor immunity. J Exp Med 2010, 207(10):2187-2194.

34. Spranger S, Spaapen RM, Zha Y, Williams J, Meng Y, Ha TT, Gajewski TF: Upregulation of $\mathrm{PD}-\mathrm{L} 1, \mathrm{IDO}$, and Tregs in the melanoma tumor microenvironment is driven by CD8+ T cells. Sci Transl Med 2013, 5(200):116-200. 
35. Kakuta S, Tagawa Y, Shibata S, Nanno M, Iwakura Y: Inhibition of B16 melanoma experimental metastasis by interferon-gamma through direct inhibition of cell proliferation and activation of antitumour host mechanisms. Immunology 2002, 105(1):92-100.

36. Correll A, Tuettenberg A, Becker C, Jonuleit H: Increased regulatory T-cell frequencies in patients with advanced melanoma correlate with a generally impaired T-cell responsiveness and are restored after dendritic cell-based vaccination. Exp Dermato/ 2010, 19(8):213-221.

37. Yanez R, Lamana ML, Garcia-Castro J, Colmenero I, Ramírez M, Bueren JA: Adipose tissue-derived mesenchymal stem cells have in vivo immunosuppressive properties applicable for the control of the graft-versus-host disease. Stem Cells 2006, 24(11):2582-2591.

38. West EE, Jin HT, Rasheed AU, Penaloza-Macmaster P, Ha SJ, Tan WG, Youngblood B, Freeman GJ, Smith KA, Ahmed R: PD-L1 blockade synergizes with IL-2 therapy in reinvigorating exhausted T cells. J Clin Invest 2013, 123(6):2604-2615.

39. Wagner $B$, Henschler R: Fate of intravenously injected mesenchymal stem cells and significance for clinical application. Adv Biochem Eng Biotechnol 2013, 130:19-37.

40. Fischer UM, Harting MT, Jimenez F, Monzon-Posadas WO, Xue H, Savitz SI, Laine GA, Cox CS Jr: Pulmonary passage is a major obstacle for intravenous stem cell delivery: the pulmonary first-pass effect. Stem Cells Dev 2009, 18(5):683-692.

41. Eggenhofer E, Benseler V, Kroemer A, Popp FC, Geissler EK, Schlitt HJ, Baan CC, Dahlke MH, Hoogduijn MJ: Mesenchymal stem cells are short-lived and do not migrate beyond the lungs after intravenous infusion. Front Immunol 2012, 3:297.

42. Kraitchman DL, Tatsumi M, Gilson WD, Ishimori T, Kedziorek D, Walczak P, Segars WP, Chen HH, Fritzges D, Izbudak I, Young RG, Marcelino M, Pittenger MF, Solaiyappan M, Boston RC, Tsui BM, Wahl RL, Bulte JW: Dynamic imaging of allogeneic mesenchymal stem cells trafficking to myocardial infarction. Circulation 2005, 112(10):1451-6110.

43. Kyriakou C, Rabin N, Pizzey A, Nathwani A, Yong K: Factors that influenceshort-term homing of human bone marrow-derived mesenchymal stem cells in axenogeneic animal model. Haematologica 2008, 93(10):1457-1465.

44. Kurtz A: Mesenchymal stem cell delivery routes and fate. Int J Stem Cells 2008, 1(1):1-7.

45. Eggenhofer E, Luk F, Dahlke MH, Hoogduijn MJ: The life and fate of mesenchymal stem cells. Front Immunol 2014, 19(5):148.

46. Kidd S, Spaeth E, Dembinski JL, Dietrich M, Watson K, Klopp A, Battula VL, Weil M, Andreeff M, Marini FC: Direct evidence of mesenchymal stem cell tropismfor tumor and wounding microenvironments using in vivo bioluminescent imaging. Stem Cells 2009, 27(10):2614-2623.

47. Li L, Jiang Q, Ding G, Zhang L, Zhang ZG, Li Q, Panda S, Lu M, Ewing JR, Chopp M: Effects of administration route on migration and distribution of neural progenitor cells transplanted into rats with focal cerebral ischemia, an MRI study. J Cereb Blood Flow Metab 2010, 30(3):653-662.

48. D'souza N, Burns JS, Grisendi G, Candini O, Veronesi E, Piccinno S, Horwitz EM, Paolucci P, Conte P, Dominici M: MSC and tumors: homing, differentiation, and secretion influence therapeutic potential. Adv Biochem Eng Biotechnol 2013, 130:209-266.

49. Comşa S, Ciuculescu F, Raica M: Mesenchymal stem cell-tumor cell cooperation in breast cancer vasculogenesis. Mol Med Rep 2012 5(5):1175-1180.

50. Groth AC, Fish M, Nusse R, Calos MP: Construction of transgenic Drosophila by using the site-specific integrase from phage phiC31. Genetics 2004, 166(4):1775-1782.

51. Marh J, Stoytcheva Z, Urschitz J, Sugawara A, Yamashiro H, Owens JB, Stoytchev I, Pelczar P, Yanagimachi R, Moisyadi S: Hyperactive selfinactivating piggyBac for transposase-enhanced pronuclear microinjection transgenesis. Proc Natl Acad Sci U S A 2012, 109(47):19184-19189.

doi:10.1186/1476-4598-13-255

Cite this article as: Bahrambeigi et al:: PhiC31/PiggyBac modified stromal stem cells: effect of interferon $\gamma$ and/or tumor necrosis factor (TNF)-related apoptosis-inducing ligand (TRAIL) on murine melanoma. Molecular Cancer 2014 13:255

\section{Submit your next manuscript to BioMed Central and take full advantage of:}

- Convenient online submission

- Thorough peer review

- No space constraints or color figure charges

- Immediate publication on acceptance

- Inclusion in PubMed, CAS, Scopus and Google Scholar

- Research which is freely available for redistribution
C Biomed Central 